\title{
Factors contributing to the development of extreme North Atlantic cyclones and their relationship with the NAO
}

\author{
Joaquim G. Pinto $\cdot$ Stefan Zacharias • \\ Andreas H. Fink · Gregor C. Leckebusch · \\ Uwe Ulbrich
}

Received: 31 October 2007/Accepted: 12 March 2008/Published online: 22 April 2008

(C) The Author(s) 2008

\begin{abstract}
The occurrence of extreme cyclones is analysed in terms of their relationship to the NAO phase and the dominating environmental variables controlling their intensification. These are latent energy (equivalent potential temperature $850 \mathrm{hPa}$ is used as an indicator), upper-air baroclinicity, horizontal divergence and jet stream strength. Cyclones over the North Atlantic are identified and tracked using a numerical algorithm, permitting a detailed analysis of their life cycles. Extreme cyclones are selected as the $10 \%$ most severe in terms of intensity. Investigations focus on the main strengthening phase of each cyclone. The environmental factors are related to the NAO, which affects the location and orientation of the cyclone tracks, thus explaining why extreme cyclones occur more (less) frequently during strong positive (negative) NAO phases. The enhanced number of extreme cyclones in positive NAO phases can be explained by the larger area with suitable growth conditions, which is better aligned with the cyclone tracks and is associated with increased cyclone life time and intensity. Moreover, strong intensification of cyclones is frequently linked to the occurrence of extreme values of growth factors in the immediate vicinity of the cyclone centre. Similar results are found for ECHAM5/ OM1 for present day conditions, demonstrating that relationships between the environment factors and cyclones are also valid in the GCM. For future climate conditions (following the SRES A1B scenario), the results are similar,
\end{abstract}

J. G. Pinto $(\bowtie) \cdot$ S. Zacharias · A. H. Fink

Institut für Geophysik und Meteorologie, Universität zu Köln,

Kerpener Str. 13, 50923 Cologne, Germany

e-mail: jpinto@meteo.uni-koeln.de

G. C. Leckebusch · U. Ulbrich

Institut für Meteorologie, Freie Universität Berlin,

Carl-Heinrich-Becker-Weg 6-10, 12165 Berlin, Germany but a small increase of the frequency of extreme values is detected near the cyclone cores. On the other hand, total cyclone numbers decrease by $10 \%$ over the North Atlantic. An exception is the region near the British Isles, which features increased track density and intensity of extreme cyclones irrespective of the NAO phase. These changes are associated with an intensified jet stream close to Europe. Moreover, an enhanced frequency of explosive developments over the British Isles is found, leading to more frequent windstorms affecting Europe.

Keywords Cyclone activity .

Anthropogenic climate change - Extreme cyclones ·

Growth factors $\cdot$ North Atlantic Oscillation

\section{Introduction}

Extratropical cyclones are one of the most important features of the climate of mid-latitudes. Their genesis occurs typically along the polar front, a hyperbaroclinic zone between the warm subtropical air masses and the cold polar air masses stretching over the mid-latitudes of both hemispheres. Over the Northern Hemisphere $(\mathrm{NH})$, a region featuring particularly strong meridional temperature gradients along this barocline zone is located over the eastern North American continent. Here, many perturbations start to develop into mature extra-tropical cyclones: They typically undergo a strong intensification phase over the North Atlantic (NA), propagate eastward and reach Europe, where they are one of the main factors influencing local weather.

Intense cyclones are often associated with extreme weather, in terms of wind and precipitation extremes (e.g. Raible et al. 2007). The January 2007 storm over Europe 
named "Kyrill" (all names herein are as used by the German weather service, DWD), for example, was associated with intense wind gusts over large parts of central Europe (Fink et al. 2008). Such storms have characteristics that distinguish them from typical cyclones (e.g. Ulbrich et al. 2001) and are an important natural hazard for Western Europe (e.g. Klawa and Ulbrich 2003).

Synoptic variability over the NA and Europe in winter is related to the North Atlantic Oscillation (hereafter NAO; Walker 1924), the dominating variability pattern over this area (e.g. Hurrell 1995; Hurrell et al. 2003). Extended reviews on phenomenology, mechanisms and variability of the NAO can be found, e.g. in Marshall et al. (2001) and Wanner et al. (2001). The links between the NAO and, e.g. cyclone activity, temperature and precipitation patterns have been extensively discussed in the literature (e.g. Marshall et al. 2001). Even though there is a link between the NAO phase and the occurrence of storms (e.g. Serreze et al. 1997; Raible 2007), the correspondence is not tight: in particular, extreme systems may also occur in negative phases. On the other hand, the cyclones themselves play a major role in steering the NAO phase (e.g. Feldstein 2003; Benedict et al. 2004; Franzke et al. 2004).

With respect to climate change, sensitivity to rising greenhouse gas concentration, eventually emerging from the strong multi-decadal variations, is found both for the NAO (e.g. Osborn 2004; Stephenson et al. 2006) and for cyclone activity (see Ulbrich et al. 2008a, for a review). In particular, Pinto et al. (2007b, hereafter P07) analysed the impact of anthropogenic climate change (ACC) to cyclone activity considering an ensemble of simulations with the ECHAM5/MPI-OM1 GCM. Results show a general decrease of cyclone activity over the $\mathrm{NH}$ midlatitudes but simultaneously an increase of cyclone intensities in certain regions, e.g. near the British Isles. They related the latter fact with the extension of jet stream and the associated barocline zone over the NA into Europe under ACC, in agreement with the more zonal orientation of storm tracks. The increased activity near the British Isles was also documented, e.g. by Bengtsson et al. (2006) for the same GCM simulations, using a different methodology. These changes in cyclone activity in ECHAM5/MPI-OM1 are associated with enhanced occurrence of wind extremes over western and central Europe (P07; Pinto et al. 2007a). Similar increases in extreme wind speeds were also detected for this area in other GCMs and several regional models, particularly between $45^{\circ} \mathrm{N}$ and $55^{\circ} \mathrm{N}$ (Leckebusch et al. 2006; Beniston et al. 2007). To assess the meaningfulness of these projections, it is of pivotal importance to investigate the representation of the observed physical processes linking the NAO and cyclone activity in GCMs, both for present and future climate conditions.
The first aim of this work is to analyse the occurrence of extreme cyclones (i.e., systems which underwent a stronger intensification) and their relationship to the NAO phase and to the dominating environmental variables controlling their intensification. In particular, we consider upper-air baroclinicity, horizontal divergence and jet stream and lowlevel latent energy (equivalent potential temperature at $850 \mathrm{hPa}$ used as an indicator). The second objective of this work is to investigate the impact of ACC in the relationships found between extreme cyclones, NAO phase and environmental variables. A short description of the data used is given in Sect. 2, while Sect. 3 describes the methodologies used. The results based on the NCEPreanalysis are presented in Sect. 4. The possible changes due to ACC are analysed on the basis of the ECHAM5/ MPI-OM1 GCM (Sect. 5). A short discussion concludes this paper.

\section{Data}

The investigations are based on NCEP-reanalysis data (Kalnay et al. 1996, hereafter NCEP). The spectral horizontal resolution is T62 and fields are available each $6 \mathrm{~h}$. In order to be consistent with previous work (e.g., Pinto et al. 2005, P07), we considered the period 1958-1998 as reference. However, results for the period 1958-2006 are equivalent. The years 1948-1957 had already been excluded from previous efforts due to the documented inhomogenies (cf. Kistler et al. 2001). Furthermore, GCM simulations of the ECHAM5/MPI-OM1 (hereafter ECHAM5) are taken into account (T63, 6 hourly data; cf. Roeckner et al. 2003; Marsland et al. 2003; Jungclaus et al. 2005; Roeckner et al. 2006). As NCEP and GCM have similar spectral and identical temporal resolution, its influence on the identified cyclone statistics (e.g., Pinto et al. 2006) can be ignored.

The GCM data is used to assess possible trends in extreme cyclones and associated variables induced by enhanced GHG forcing. With this aim, both simulations for the recent climate (with historical forcing, hereafter 20C) and enhanced GHG-forcing (A1B scenario, hereafter A1B, cf. Nakićenović et al. 2000) are considered. Three ensemble runs per scenario are analysed. Climate signals refer to the changes between the end of the twenty-first century (20602100) and recent climate conditions (1960-2000) in terms of ensemble averages. For all investigations, the analysis period is the winter half year (October-March), as the most intense storms affecting NA and Europe occur not only in peak winter but also in late autumn and early spring (cf. Klawa and Ulbrich 2003, their Table 4).

The cyclone statistics for NCEP were computed by Pinto et al. (2005, hereafter P05) based on a tracking algorithm by 
Murray and Simmonds (1991) adapted to NH conditions. The ECHAM5 GCM cyclone statistics were obtained by P07 considering several SRES scenarios. Both studies considered the whole $\mathrm{NH}$ (north of $20^{\circ} \mathrm{N}$ ) as study area.

\section{Methods}

\subsection{Considerations of cyclone tracks}

The basic dataset for investigation is the cyclone track climatology described in P05. Cyclones are identified and tracked using mean sea level pressure (MSLP), and the intensity of cyclones is given by the associated value of the Laplacian of the MSLP (denoted $\nabla^{2} p$ ), which is proportional to relative vorticity. The obtained $\mathrm{NH}$ cyclone climatology fulfils the following conditions:

- Cyclones must have a lifetime of at least $24 \mathrm{~h}$.

- Systems localised in areas with a terrain-height of 1,500 $\mathrm{m}$ above sea level or more are excluded.

- At least once in its lifetime, cyclone intensity must exceed a minimum threshold of $0.6 \mathrm{hPa}$ deg.lat. ${ }^{-2}$ and be associated with a "true" pressure minimum.

For a more detailed explanation on the current settings of the algorithm and its implications, the reader is referred to P05. For this study, only a subset of the cyclone climatology is considered. Further constraints are added:

1. The cyclone track crosses the NA basin and Europe (area defined as $70^{\circ} \mathrm{W}-40^{\circ} \mathrm{E}, 30^{\circ} \mathrm{N}-75^{\circ} \mathrm{N}$ ) during its lifetime.

2. The cyclone features an intensification phase (measured in terms of $\left.\mathrm{d} / \mathrm{d} t\left(\nabla^{2} p\right)\right)$ within this area. The minimum threshold is $0.3 \mathrm{hPa}$ deg.lat. ${ }^{-2}$ day $^{-1}$ (within a 24-h period).

The second condition removes $33.2 \%$ of the initially detected cyclone tracks. In order to select the most intense systems, a further constraint is added:

3. The cyclone belongs to the strongest $10 \%$ cyclones in terms of maximum cyclone intensity (measured as $\nabla^{2} p$ ) during its lifetime.

Conditions (2) and (3) must be fulfilled within the area defined in condition (1). Cyclones fulfilling all three conditions are hereafter denominated "extreme cyclones". This subset of cyclones includes roughly $6.68 \%$ of the cyclones from $\mathrm{P} 05$ which cross the study area. The threshold $\nabla^{2} p$ value for extreme cyclones is $2.67 \mathrm{hPa}$ deg.lat. ${ }^{-2}$. All cyclones fulfilling (1), (2) but not (3) are denoted as "non-extreme cyclones". This subset of cyclones will be analysed in comparison to "extreme cyclones" as a reference. The considered cyclone variables are cyclone track density (number and length of cyclone tracks), cyclone intensity (averaged $\nabla^{2} p$ ) and cyclogenesis (number of originating cyclones), all computed over a $7.5^{\circ}$ radius for each grid point. The mean values for NCEP are shown in P05 and/or P07.

\subsection{Considerations of the NAO}

Furthermore, the role of the NAO phase during the development of extreme cyclones is considered. The NAO pattern is derived from monthly mean data (via Principal Component Analysis of SLP) for the area $90^{\circ} \mathrm{W}-50^{\circ} \mathrm{E}$, $20^{\circ} \mathrm{N}-80^{\circ} \mathrm{N}$. As expected, the NAO is the leading principal component for this area (EOF shown in Fig. 1a). A comparison between the obtained monthly index (the associated first principal component) and the station-based index by Jones et al. (1997) shows a linear correlation of 0.82 (both time series are shown in Fig. 1b). In order to examine the relationship between the NAO and individual cyclones, we have constructed a "daily NAO index". This daily index is obtained by projecting the monthly pattern onto the daily SLP data, followed by a 5-day running mean smoothing. This approach for achieving a daily NAO index is similar to the method used by Blessing et al. (2005). An example for the resulting time series is shown in Fig. 1c (winter 1989/ 1990). Also indicated are the dates of occurrence of two important storms over central Europe in early 1990, namely "Daria" and "Vivian", which were both associated with high values of the daily NAO index. The assignment of the historical storms to a NAO phase is based on the definitions given in Table 2 ("neutral", "positive", "negative", "strong positive", "strong negative"), enabling composite studies between the different phases.

The relationship between the cyclones and the NAO works both ways: Benedict et al. (2004) and Franzke et al. (2004) gave evidence that the anomalies of both NAO phases are remnants of breaking synoptic-scale waves (cf. also Thorncroft et al. 1993). Even without wave breaking, travelling cyclones may project on the NAO, as documented, e.g., by Sickmöller et al. (2000), Löptien and Ruprecht (2005) and Schneidereit et al. (2007). The averaging of the NAO index over 5 days considered here minimises the influence of individual systems in the NAO index.

\subsection{Considerations of environmental variables influencing cyclone growth}

The next step is to assign the development phase of each cyclone to the environmental variables, similar to the analysis, e.g., by Schultz et al. (1998) and Ulbrich et al. (2001). Four parameters are considered to study the largescale atmospheric conditions in which the cyclones are embedded: 
- The Eady growth rate (e.g., Hoskins and Valdes 1990) is a measure of baroclinicity, calculated as $\sigma_{\mathrm{BI}}=0.31(f / N)|\mathrm{d} v / \mathrm{d} z|$, where $f$ is the Coriolis parameter, $N$ is the static stability, $z$ the vertical coordinate and $v$ the horizontal wind vector. It quantifies the largescale conditions for the potential growth of cyclones, and gives a rather good approximation of wave growth in observations even with longitudinally variable mean flow (Hoskins and Hodges 2002). We computed this quantity both for the upper (300-500 hPa) and lower (700-850 hPa) troposphere. However, as the anomalies associated with the development of cyclones typically
Fig. 1 NAO definition for NCEP. a Leading MSLP EOF for North Atlantic/Europe $\left(90^{\circ} \mathrm{W}-50^{\circ} \mathrm{E} ; 20^{\circ} \mathrm{N}-80^{\circ} \mathrm{N}\right)$ using latitude weighting for NCEP data (1958-1998). Explained variance is $36.14 \%$, period is October-March. b Monthly NAO indices, first PC (black), Jones et al. (1997) (grey). c Example for daily NAO index for the winter 1989/ 90 , including the period of occurrence of extra-tropical storms over Central Europe. The grey areas correspond to the periods of occurrence of Storm Daria (1) and Vivian (2), the day of maximum intensification is shaded dark grey
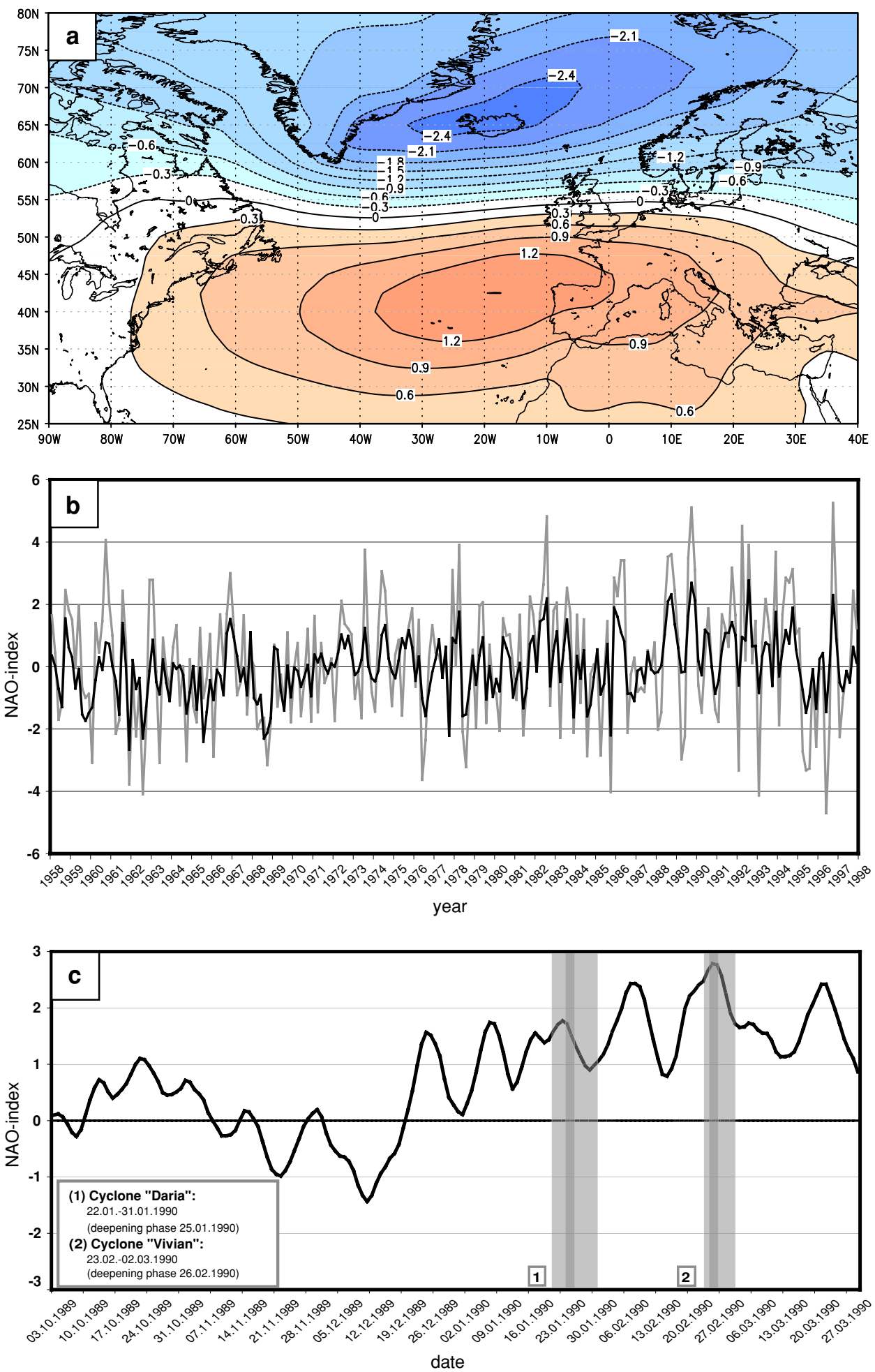
occur simultaneously for both variables, we omit statistics on the latter. The upper-air Eady growth rate is hereafter denoted as $\sigma_{400}$. This variable is considered as 3-day running averages, including the 24 -h period of strongest development and the previous $48 \mathrm{~h}$ (e.g., the value for day $4,12 \mathrm{UTC}$, is a running average from day 1 12UTC to day 4, 12 UTC). This choice is based on lagged correlations studies (not shown) and the previous experience by the authors (e.g., Ulbrich et al. 2001).

- The upper-air jet stream $(250 \mathrm{hPa})$, as the flow at upper levels has a strong influence on the steering and velocity of cyclone development (e.g., Kurz 1990). This variable corresponds to the wind speed at $250 \mathrm{hPa}$, and is hereafter denoted as jet 250 .

- The upper-air divergence $(250 \mathrm{hPa})$, as areas of intense divergence north of the jet exit region are well known to induce rapid cyclone growth (e.g., Uccellini and Johnson 1979; Baehr et al. 1999; Ulbrich et al. 2001). It is hereafter denoted as $\operatorname{div}_{250}$.

- The equivalent-potential temperature at $850 \mathrm{hPa}$ (computed according to a formula given in Bolton 1980) is used as an indicator of the combined effect of latent and sensible heat, which may also contribute to cyclone intensification (e.g., Chang et al. 1984). It is hereafter denoted as $\theta_{\mathrm{e}}$.

In a first step, the most intense strengthening phase of a cyclone is identified, defined as the 24-h period when the intensity enhancement is maximised. The development of cyclones in association with the four environment variables is not always straightforward: For example, high local jet wind speed do not necessarily produce intense cyclones, as development is strongly sensitive to the relative position of the cyclone versus the jet itself (cf. development of storm "Lothar", Ulbrich et al. 2001). Following the analysis of similar case studies, the influence of $\theta_{\mathrm{e}}, \mathrm{jet}_{250}$ and $\operatorname{div}_{250}$ appear to be "effective" to the cyclone development within a very short time lag (apparently a few hours), as seen in the explosive development of "Lothar" at this point (Ulbrich et al. 2001; their Figs. 2, 4). Therefore, the consideration of the 24-h of maximum development is found reasonable. Therefore, for each individual cyclone, the five values during the 24-h period of strongest development of all four environmental variables are considered.

As an example, detailed information on the life cycle of storm "Daria" is shown in Table 1. The strongest intensification occurred between January 24th, 18 UTC and

Table 1 Life cycle of storm "Daria"

\begin{tabular}{|c|c|c|c|c|c|c|c|c|}
\hline Date & Time & Longitude & Latitude & Core pressure & $\nabla^{2} p$ & $\mathrm{~d} / \mathrm{d} t(? ? \mathrm{CP})$ & $\mathrm{d} / \mathrm{d} t\left(\nabla^{2} p\right)$ & \# \\
\hline 19900123 & 00 & 303.85 & 40.42 & $1,011.20$ & 0.652 & 2.68 & -0.110 & \\
\hline 19900123 & 06 & 304.51 & 41.00 & $1,010.81$ & 0.719 & -0.39 & 0.067 & \\
\hline 19900123 & 12 & 306.03 & 42.07 & $1,011.27$ & 0.642 & 0.46 & -0.077 & \\
\hline 19900123 & 18 & 309.34 & 43.59 & $1,008.94$ & 0.818 & -2.33 & 0.176 & \\
\hline 19900124 & 00 & 315.81 & 45.69 & $1,007.85$ & 0.977 & -1.09 & 0.159 & \\
\hline 19900124 & 06 & 320.06 & 47.24 & $1,002.83$ & 1.095 & -5.02 & 0.118 & \\
\hline 19900124 & 12 & 325.74 & 48.48 & 996.82 & 1.339 & -6.01 & 0.244 & \\
\hline 19900124 & 18 & 333.36 & 49.84 & 986.66 & 1.600 & -10.16 & 0.261 & 1 \\
\hline 19900125 & 00 & 343.05 & 51.38 & 976.18 & 1.921 & -10.48 & 0.321 & 2 \\
\hline 19900125 & 06 & 350.40 & 53.23 & 963.70 & 2.218 & -12.48 & 0.297 & 3 \\
\hline 19900125 & 12 & 356.96 & 54.73 & 954.49 & 2.850 & -9.21 & 0.632 & 4 \\
\hline 19900125 & 18 & 1.98 & 56.17 & 946.98 & 3.432 & -7.51 & 0.582 & 5 \\
\hline 19900126 & 00 & 5.38 & 57.25 & 948.58 & 3.058 & 1.60 & -0.374 & \\
\hline 19900126 & 06 & 8.20 & 58.06 & 955.28 & 2.461 & 6.70 & -0.597 & \\
\hline 19900126 & 12 & 11.94 & 58.68 & 962.18 & 1.984 & 6.90 & -0.477 & \\
\hline 19900126 & 18 & 16.29 & 59.37 & 965.77 & 1.877 & 3.59 & -0.107 & \\
\hline 19900127 & 00 & 20.63 & 59.96 & 970.28 & 1.900 & 4.51 & 0.023 & \\
\hline 19900127 & 06 & 24.92 & 61.11 & 974.15 & 1.731 & 3.87 & -0.169 & \\
\hline 19900127 & 12 & 28.16 & 61.85 & 978.62 & 1.396 & 4.47 & -0.335 & \\
\hline 19900127 & 18 & 32.34 & 62.90 & 982.81 & 1.070 & 4.19 & -0.326 & \\
\hline
\end{tabular}

Date (YYYYMMDD), time (UTC), longitude $\left({ }^{\circ} \mathrm{E}\right)$, latitude $\left({ }^{\circ} \mathrm{N}\right)$, core pressure $(\mathrm{hPa})$, laplacian of pressure $\left(\nabla^{2} p\right)\left(\mathrm{hPa}\right.$ deg. lat. $\left.{ }^{-2} 0\right)$, core pressure tendency $(\mathrm{d} / \mathrm{d} t(\mathrm{CP}))\left(\mathrm{hPa}\right.$ day $\left.{ }^{-1}\right)$, laplacian of pressure tendency $\left(\mathrm{d} / \mathrm{d} t\left(\nabla^{2} p\right)\right)\left(\mathrm{hPa}\right.$ deg. lat. $^{-2}$ day $\left.^{-1}\right)$, numeration for positions during the intensification phase (\#) 
January 25th, 18 UTC (in bold in Table 1) as cyclone intensity increased from 1.6 to $3.4 \mathrm{hPa}$ deg.lat. ${ }^{-2}$. During this period of time, the cyclone approaches the British Isles (cf. Fig. 2); the central position (January 25th, 06 UTC, cf. third position in Table 1, last row) is marked with a blue circle. Also shown as isolines in Fig. 2 are the corresponding 3-day running averages of $\sigma_{400}$ (Fig. 2a), and non-averaged values of jet ${ }_{250}$ (Fig. 2b), $\operatorname{div}_{250}$ (Fig. 2c) and $\theta_{\mathrm{e}}$ (as an indicator for latent energy, Fig. 2d) for January 25 th, 06 UTC. These show extreme values near the cyclone during this time window (exceeding the long-term 95th and 99th percentile, denoted in colour in Fig. 2), indicating that the strong intensification of storm Daria $\left(-40 \mathrm{hPa} \mathrm{day}^{-1}\right.$ and $+1.8 \mathrm{hPa}$ deg.lat. ${ }^{-2}$ day $^{-1}$ ) was associated with excellent conditions for cyclone development (extreme values of environmental variables). This analysis is then extended for the whole cyclone database: the environmental variables during the strengthening phase $(24 \mathrm{~h}$ time window, hence five values) of each cyclone are considered, thus enabling composite studies (cf. Sect. 4).

\section{Results based on reanalysis data}

\subsection{Cyclone activity}

The characteristics of cyclone activity for extreme cyclones versus non-extreme cyclones (as defined in the previous section) are analysed. The cyclone track density for nonextreme cyclones shows a maximum between the tip of Greenland and Iceland (Fig. 3a, reaching 37 cyclone days/ winter), with a secondary maximum over the western Mediterranean. The frequencies of extreme cyclones are typically lower and more limited in terms of spatial distribution (Fig. 4a), with a maximum of 13 cyclone days/ winter southwest of Iceland. Please note that the isoline interval is different in Figs. 3 and 4. Further insight is gained by comparing the average cyclone intensity between the two categories of cyclones: While the values and patterns for non-extreme cyclones (Fig. 3b) are similar to the statistics in P07 (their Fig. 1h, which additionally includes non-developing systems), with slightly lower magnitudes,
Fig. 2 Case study for storm "Daria", 25.01.1990, 06 UTC: a Eady growth rate $400 \mathrm{hPa}$ $\left(\right.$ day $\left.^{-1}\right)$ as 3-day running mean, b Jet stream $250 \mathrm{hPa}\left(\mathrm{m} \mathrm{s}^{-1}\right)$, c Horizontal divergence $250 \mathrm{hPa}\left(\mathrm{s}^{-1}\right)$, d equivalent potential temperature $850 \mathrm{hPa}$ (K). Exceedance of the longterm 95th and 99th percentile is denoted in colour. For all panels, cyclone track in blue, position at 25 January 1990, 06 UTC marked with circle (500 km around core). Detailed information on track are given in Table 1
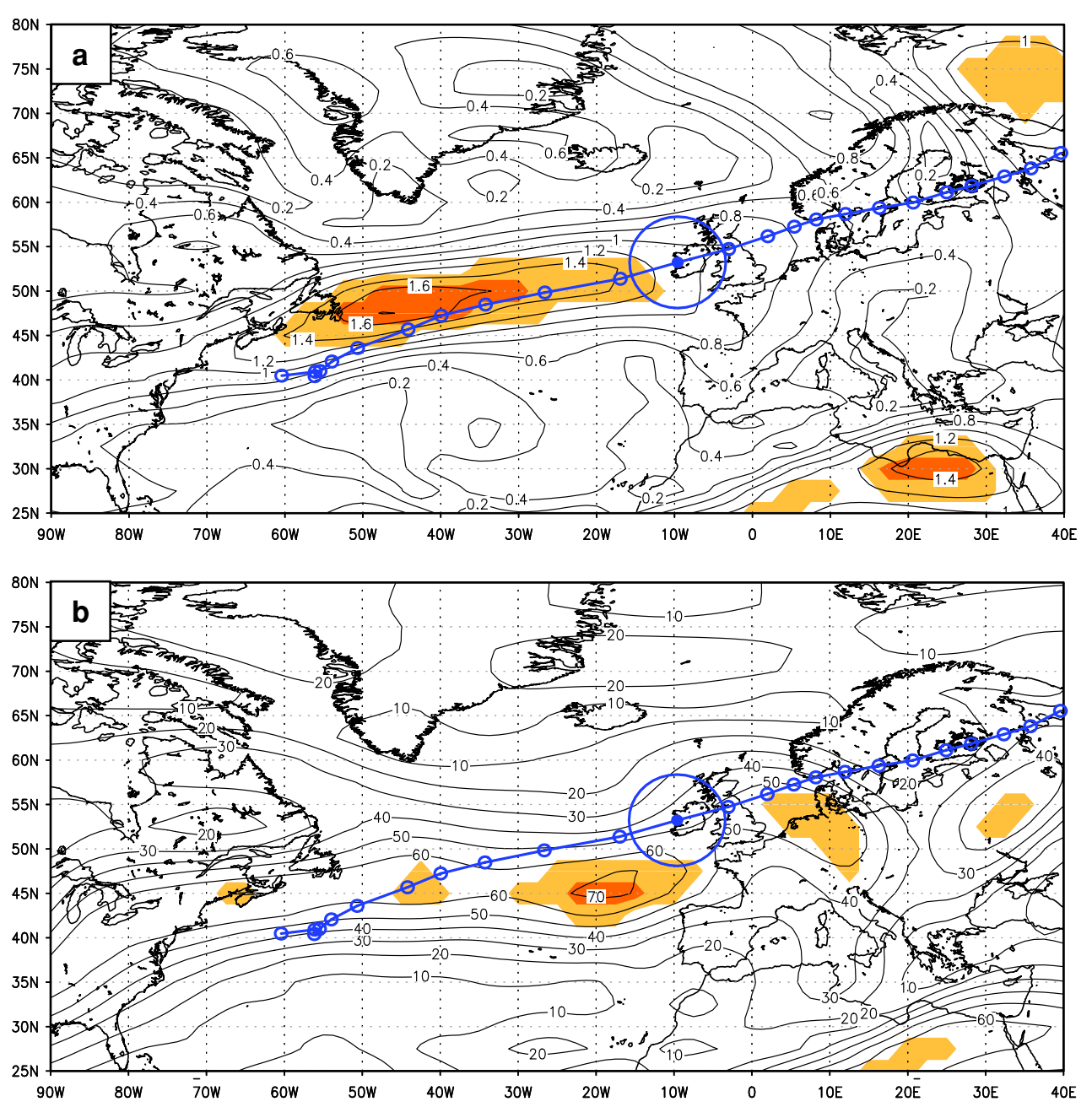
Fig. 2 continued
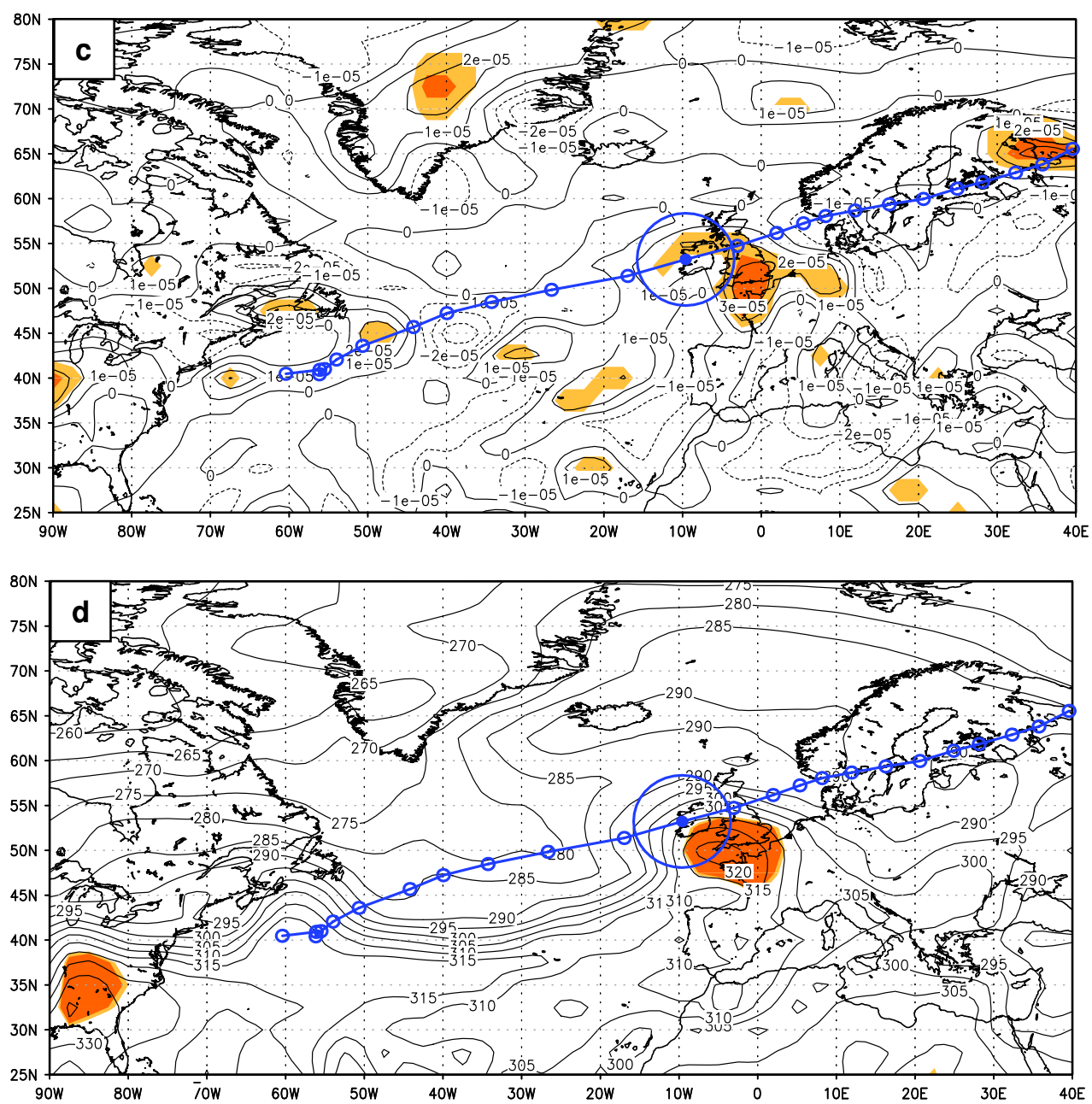

the results for extreme cyclones show much larger intensity values (Fig. 4b), exceeding $2 \mathrm{hPa}$ deg.lat. ${ }^{-2}$ between Newfoundland and Greenland. Figure $4 \mathrm{~b}$ also depicts the average $j t_{250}$, revealing a good agreement with cyclone statistics: e.g., maximum cyclone intensity values are located downstream of the maximum of jet 250 . Moreover, two distinct maxima of cyclogenesis for cyclones becoming extreme during their lifetime are found, one at North America's east coast and one west of Iceland (Fig. 4c). Naturally, both areas are also genesis areas for non-extreme cyclones, but Fig. $3 \mathrm{c}$ indicates that the North American East coast is comparatively less important, while two other regions of origin can be identified (Mediterranean, west of Greenland) which do not play a role for the extreme systems. In fact, the quotient of cyclogenesis counts of extreme cyclones and cyclogenesis counts of non-extreme cyclones is largest around $35^{\circ} \mathrm{N}, 75^{\circ} \mathrm{W}$, indicating the area just off the US east coast as preferred location for genesis of extreme cyclones (cf. also Trigo 2006, who identified the same area as the most frequent location for explosive cyclogenesis, their Fig. 3). The close agreement between cyclogenesis, cyclone track density and cyclone intensity patterns for extreme cyclones is documented in our Fig. 4: the intensity maximum (Fig. 4b) is located downstream from the cyclogenesis maximum (Fig. 4c), while the track density maximum (Fig. 4a) is located further downstream.

Further, we have analysed in how far the minimum core pressure, lifetime and track lengths are different between extreme and non-extreme cyclones (Fig. 5). Indeed, extreme cyclones do not only have a higher intensity (per definition a $\nabla^{2} p$ value above $2.67 \mathrm{hPa}$ deg.lat. ${ }^{-2}$ ) but also have typically deeper core pressures (Fig. 5a), longer lifetimes (Fig. 5b) and longer track lengths (Fig. 5c).

\subsection{Association with NAO phases}

Cyclone characteristics are analysed in terms of the associated NAO phase. Based on the defined five NAO phases (cf. Table 2), Table 3 shows the number of cyclones is largest for the neutral phase (index values between -0.5 and +0.5 ), and lowest for the NAO++ (index values above +1.5 ) and NAO-- phases (index values below -1.5 ). Table 3 also documents that the distribution of extreme cyclones (column 3) in terms of the NAO phase is skewed to larger NAO 
Fig. 3 Characteristics of nonextreme cyclones over the North Atlantic and Europe for NCEP (1958-1998). a Cyclone track density (cyclone days/winter), b cyclone intensity $\left(\nabla^{2} p\right)$ (hPa deg.lat. ${ }^{-2}$ ), c cyclogenesis (events/winter)
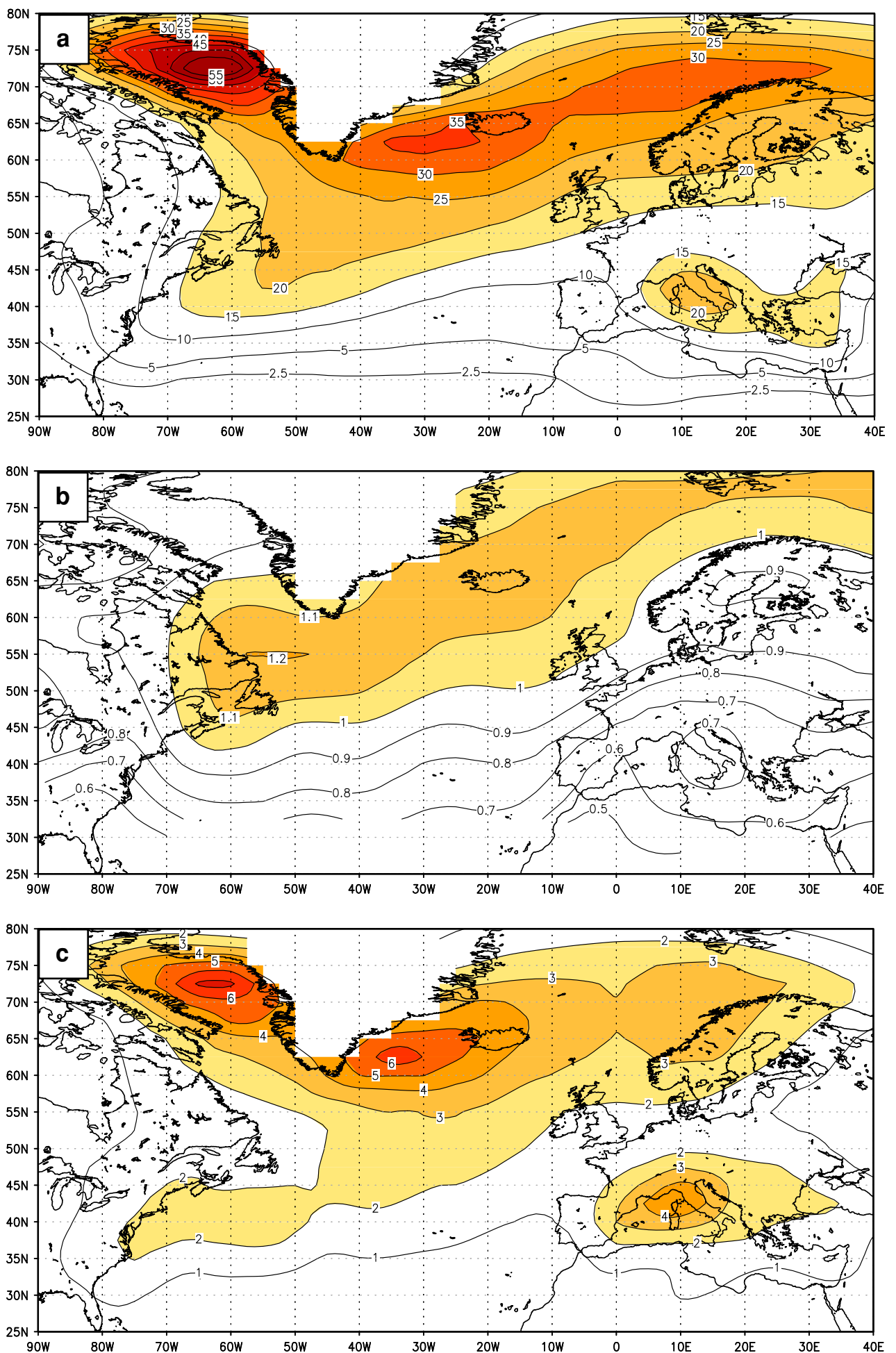

Both the occurrence of extreme and non-extreme cyclones is related to the NAO phase. In particular, there is a northeast shift of the cyclone tracks in positive NAO phases (cf. Fig. 6 vs. Fig. 7). However, the cyclone track density of extreme cyclones is more focused regionally than that of non-extreme cyclones, particularly in the NAO-- phase (compare, e.g., Fig. 7a and b). Both Figs. 6 and 7 show 
Fig. 4 Characteristics of extreme cyclones over the North Atlantic and Europe for NCEP (1958-1998). a Cyclone track density (cyclone days/winter), b cyclone intensity $\left(\nabla^{2} p\right)$ (hPa deg.lat. ${ }^{-2}$ ), c cyclogenesis (events/winter). Jet stream (wind at $250 \mathrm{hPa}$ ) mean field shown in $\mathbf{b}\left(\mathrm{m} \mathrm{s}^{-1}\right)$
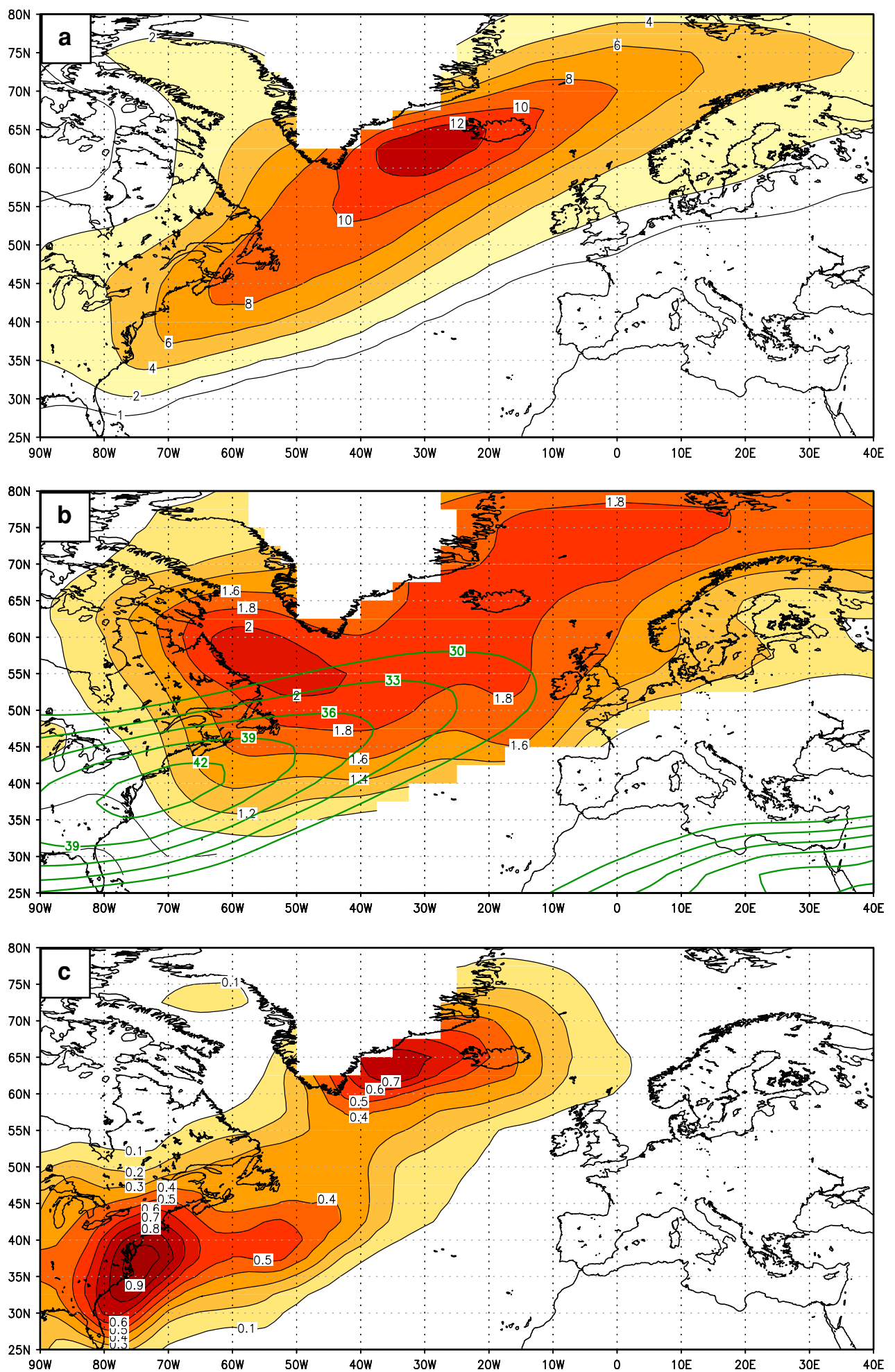

relative frequencies of cyclone track density (i.e., cyclone numbers divided by the total number of cyclones for the same NAO phase) rather than absolute values, in order to make the data more comparable between the panels. Comparing the two NAO phases, the larger magnitudes of cyclone density are located further downstream in the $\mathrm{NAO}++$ phase
(Fig. 6) in agreement with expectations (e.g., Ueno 1993; Rogers 1997; Sickmöller et al. 2000).

Next, we analysed the characteristics of extreme cyclones in terms of intensity $\left(\nabla^{2} p\right)$, minimum core pressure, lifetime and track lengths for the NAO++ and $\mathrm{NAO}--$ phases (Fig. 8). The results show that extreme cyclones on the 

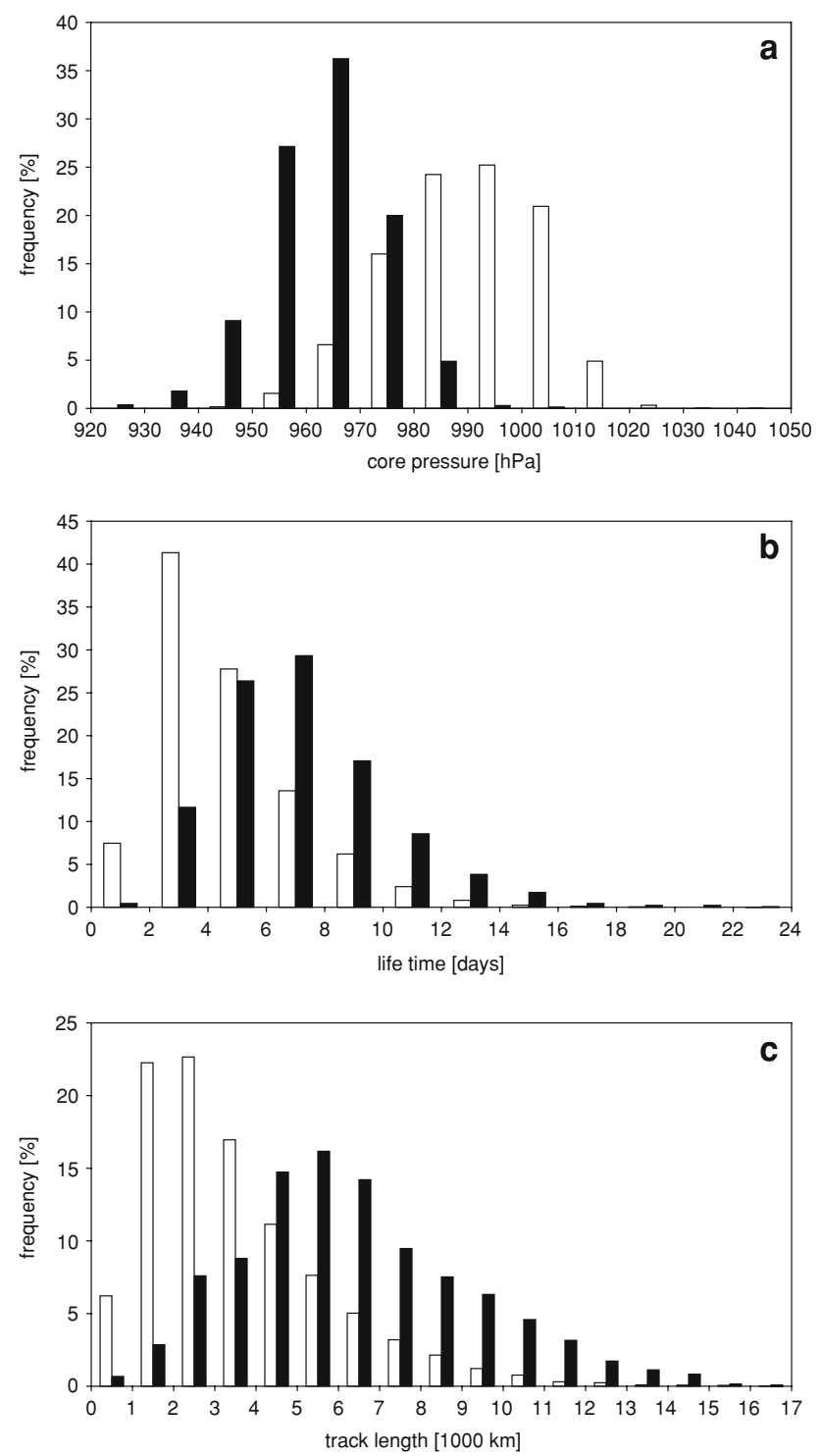

Fig. 5 Characteristics of extreme cyclones versus non-extreme cyclones over the North Atlantic and Europe for NCEP (19581998). a Minimum core pressure (hPa), b lifetime (days), c track length $(1,000 \mathrm{~km})$. Black bars correspond to extreme cyclones, white bars to non-extreme cyclones

$\mathrm{NAO}++$ phase have typically higher intensities (Fig. 8a), lower core pressures (Fig. 8b), longer lifetimes (Fig. 8c) and longer track lengths (Fig. 8d). These results suggest that extreme cyclones in the $\mathrm{NAO}++$ phase typically have a more intense/longer intensification phase. This aspect will be regarded in more detail in the next section. Results for nonextreme cyclones are similar, but differences between the NAO phases are smaller compared to extreme cyclones.

\subsection{Association with large-scale parameters} influencing cyclone growth

Composites of growth factors for extreme cyclones are considered for the NAO++ (Fig. 9) and NAO-- (Fig. 10)
Table 2 Definition of NAO phases

\begin{tabular}{lllrc}
\hline & Phase & Index values & \# days & $\%$ days \\
\hline NAO-- & Strong negative & Index $<-1.5$ & 520 & 7.3 \\
NAO- & Negative & $-1.5 \leq$ Index $<-0.5$ & 1,568 & 22.0 \\
NAO 0 & Neutral & $-0.5 \leq$ Index $<+0.5$ & 2,821 & 39.6 \\
NAO+ & Positive & $+0.5 \leq$ Index $<+1.5$ & 1,771 & 24.8 \\
NAO ++ & Strong positive & Index $\geq+1.5$ & 450 & 6.3
\end{tabular}

Index values based on the first $\mathrm{PC}$ for North Atlantic/Europe $\left(90^{\circ} \mathrm{W}-\right.$ $50^{\circ} \mathrm{E} ; 20^{\circ} \mathrm{N}-80^{\circ} \mathrm{N}$ ); number of days for NCEP falling into each NAO phase; percentage of days falling into each NAO phase

Table 3 Average statistics for NCEP (1958-1998)

\begin{tabular}{lllll}
\hline Phase & ALL & N-EXT & EXT & QUOTIENT \\
\hline NAO-- & $7.6 \%$ & $7.9 \%$ & $4.1 \%$ & $5.4 \%$ \\
NAO- & $21.9 \%$ & $22.6 \%$ & $15.5 \%$ & $7.1 \%$ \\
NAO 0 & $40.1 \%$ & $39.9 \%$ & $41.4 \%$ & $9.7 \%$ \\
NAO+ & $24.7 \%$ & $24.1 \%$ & $30.2 \%$ & $12.2 \%$ \\
NAO++ & $5.8 \%$ & $5.4 \%$ & $8.7 \%$ & $14.9 \%$ \\
Tracks total: & 13,349 & 12,019 & 1,330 &
\end{tabular}

ALL, Percentage of all cyclones per NAO phase; N-EXT, percentage of non-extreme cyclones per NAO phase; EXT, percentage of extreme cyclones per NAO phase; QUOTIENT, quotient extreme versus all cyclones per NAO phase

The values are given as a percentage of the total number of cyclones (cf. last row). The percentages of each column sum to $100 \%$. Last row: total number of cyclone tracks in the data set (40 winters)

phases. For more insight, the individual tracks are displayed (rather than the cyclone track density values presented in Figs. 6 and 7). For each track, the central position of the strengthening phase is marked with a blue dot. In the $\mathrm{NAO}++$ phase (Fig. 9), the area with excellent growth conditions (high values of jet ${ }_{250}, \sigma_{400}$ ) extends from the North American East Coast up to Northern Europe. For negative NAO phases (Fig. 10), the correspondent area is roughly limited to the western NA up to $50^{\circ} \mathrm{N}, 30^{\circ} \mathrm{W}$. Hence, a main difference is that the area with suitable growth conditions is larger in the NAO++ phase than in the NAO-phase. Moreover, the pattern of the area fits well the cyclone tracks in the $\mathrm{NAO}++$ phase, thus effectively leading to more favourable conditions for growth of cyclones during their lifetime. This assessment is in agreement with a higher percentage of intense, deep and long lasting cyclones in the $\mathrm{NAO}++$ phase (cf. Fig. 8). The differences between the two NAO phases for $\theta_{\mathrm{e}}$ (Figs. 9c, 10c) and $\operatorname{div}_{250}$ (not shown) are apparently not so evident. Please note that the strong latitudinal gradient of $\theta_{\mathrm{e}}$ also plays a role in the statistics: The latitudinal shifts of the cyclone tracks associated with the NAO phase imply that the average background $\theta_{\mathrm{e}}$ values in the cyclone environment may be quite different. However, 
Fig. 6 Cyclone track density over the North Atlantic and Europe for the $\mathrm{NAO}++$ phase (NCEP, 1958-1998). a Nonextreme cyclones; $\mathbf{b}$ extreme cyclones. Cyclone track density given as relative frequencies (i.e., cyclone numbers divided by the total number of cyclones for the same NAO phase) for easier comparison between the panels. Factors are a 649 and b 116 , which correspond to the total number of systems over 40 winters of this type in this NAO phase
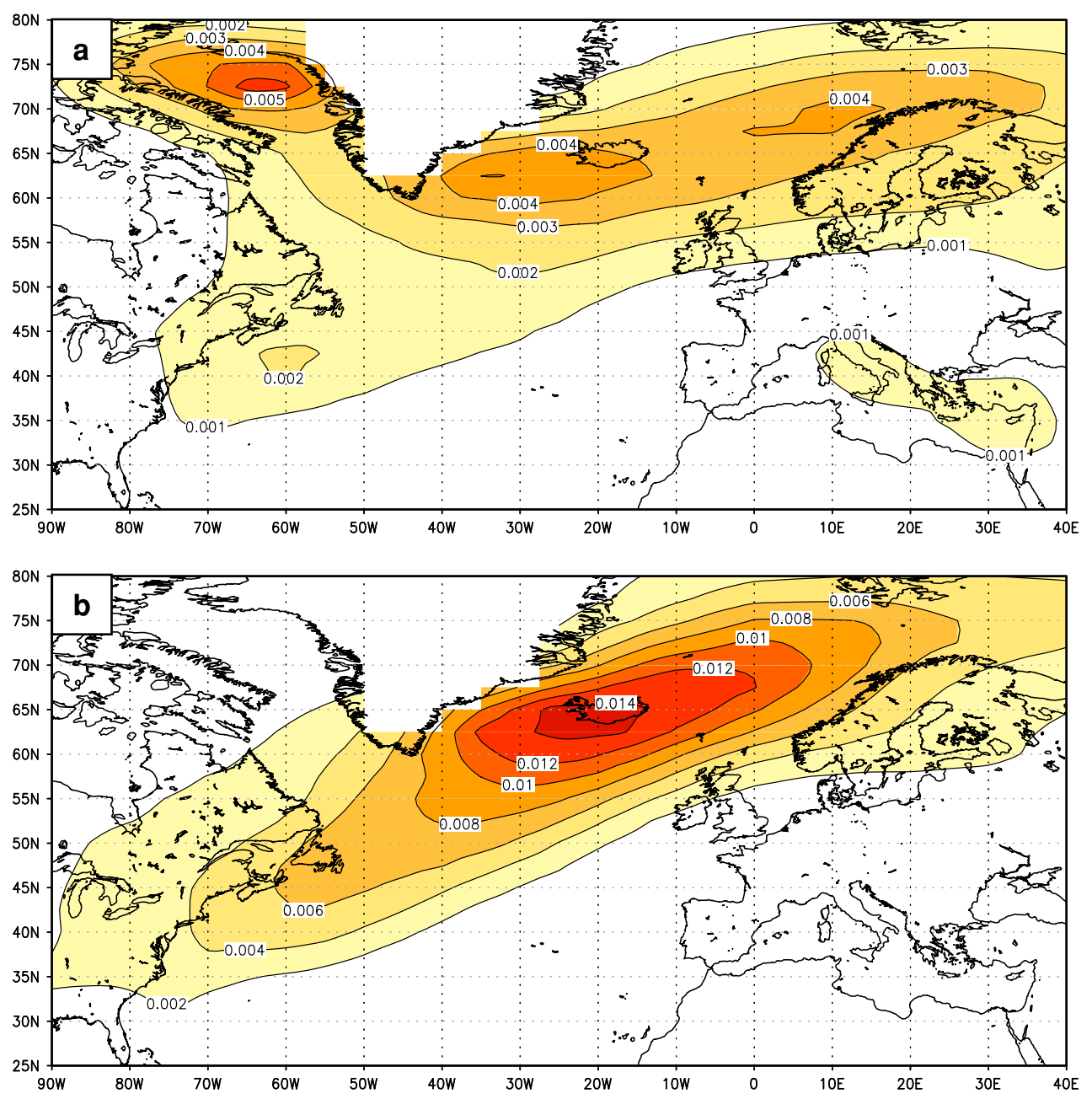

when looking at the associated growth factors for individual cyclones (within a radius of $500 \mathrm{~km}$ around the core, as circle in Fig. 2) during the intensification phase, extreme cyclones show a higher percentage of extreme values $(>95$ th percentile) than non-extreme systems. This is valid for all four environmental variables and all NAO phases (Table 4). Hence, the presented data gives evidence of the importance of the growth conditions irrespective of the NAO phase.

Further insight is gained when considering the environmental variables during the maximum intensification phase for the extreme cyclones from a Lagrangian perspective. Figure 11 shows statistics of exceedance of the local 95th percentile of each environmental variable in a $40^{\circ} \times 40^{\circ}$ box centred on the individual cyclone position. The values are given in terms of percentage of cyclones showing an extreme value for a certain grid point relative to the cyclone position. The central location corresponds to the third position of five during the intensification phase (cf. Table 1, last row). All NAO phases and only extreme cyclones are considered. Note that maximum intensification is usually reached before maximum intensity. For example, Fig. 11d shows that over $13 \%$ of the extreme cyclones feature extreme values of $\theta_{\mathrm{e}}$ about $500 \mathrm{~km}$ southeast of the cyclone core. The significance of the results was tested using the bootstrap method (which is independent from the distribution) ${ }^{1}$. Please note that part of the structures shown in Fig. 11 may be attributed to a feedback from the cyclone itself to the environmental variables.

These average patterns document that strong strengthening phases (hence resulting in extreme cyclones) are associated with, e.g., extreme values of jet 250 and $\sigma_{400}$ southwest of the cyclone position. As the typical track direction is roughly east-northeast (angle ca. $70^{\circ}$ ), this means, e.g., for Fig. 11a that the core of the "average extreme cyclone" has just crossed the barocline zone. The

\footnotetext{
${ }^{1}$ A total of 1,000 synthetic series of values of the four environmental variables were generated based on NCEP. Each contains 6,650 individual values $(1,330$ cyclones $\times 5$ values per intensification phase), for a representative grid point $\left(30^{\circ} \mathrm{W}, 60^{\circ} \mathrm{N}\right)$. Next, the frequency of exceedance of the 95th percentile of the NCEP data was compared to the correspondent values of the 1,000 synthetic series. A significance level of $95 \%$ (99\%) indicates that a maximum of 50 (10) generated series have a larger frequency of exceedance of environmental variables than the original NCEP data.
} 
Fig. 7 Cyclone track density over the North Atlantic and Europe for the NAO-- phase (NCEP, 1958-1998). a Nonextreme cyclones; b extreme cyclones. Cyclone track density given as relative frequencies (i.e., cyclone numbers divided by the total number of cyclones for the same NAO phase) for easier comparison between the panels. Factors are a 949 and b 55 , which correspond to the total number of systems over 40 winters of this type in this NAO phase
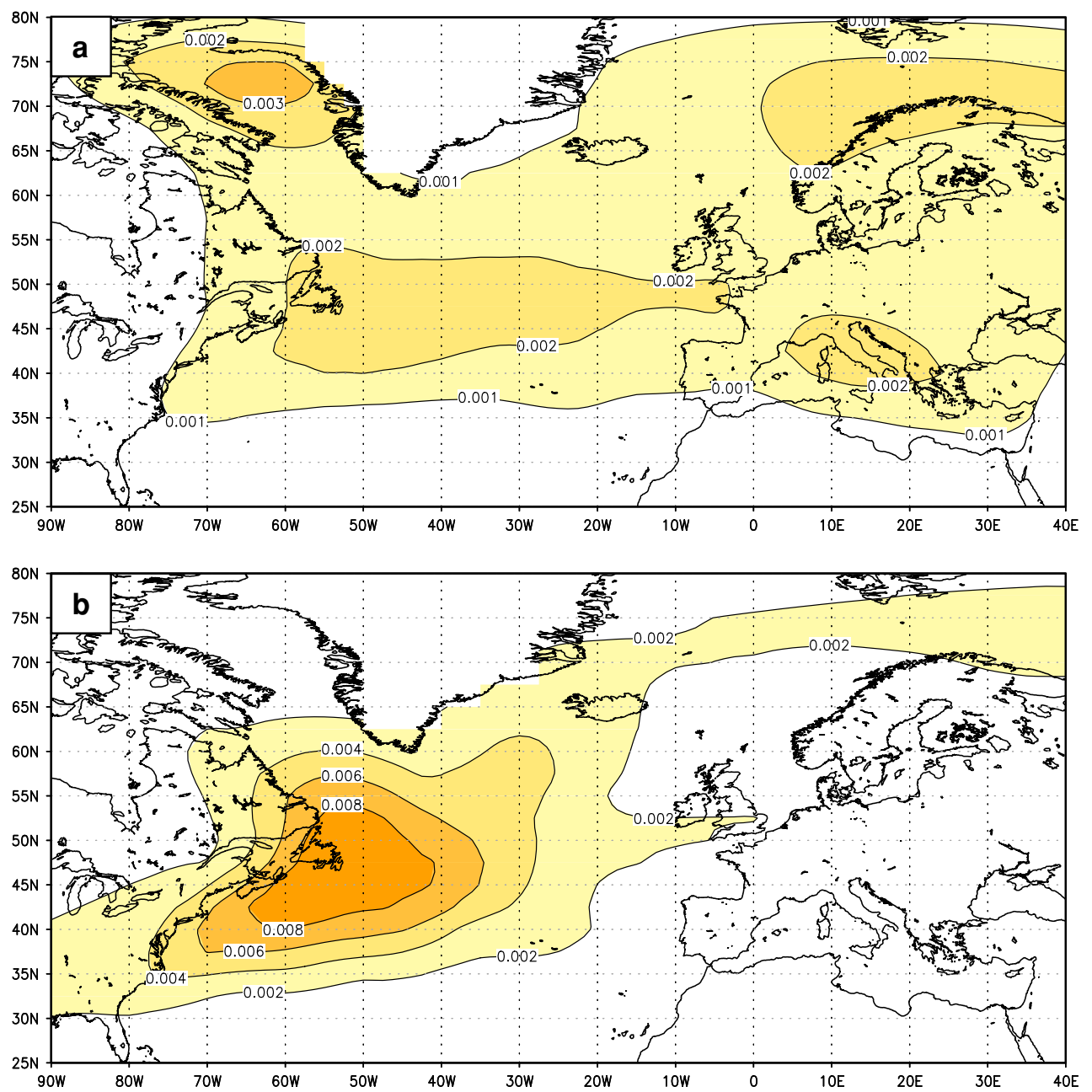

distribution of extreme values for $\operatorname{div}_{250}$ shows some of the largest values of all four variables (together with jet 250 ), with over $15 \%$ northeast of the cyclone core. This corroborates with the result presented in Table 4, where extreme values of $\operatorname{div}_{250}$ are found for $96 \%$ of all extreme cyclones within a $500 \mathrm{~km}$ radius around the core (correspondent to the circle in Fig. 11). Moreover, the role of $\operatorname{div}_{250}$ for cyclone intensification (measured as $\mathrm{d} / \mathrm{d} t\left(\nabla^{2} p\right)$ over $\left.24 \mathrm{~h}\right)$ is documented when considering scatter plots, as the data shows a near linear relationship between the two variables (not shown; the same conclusion is valid for the other three growth factors when using scatter plots). In terms of the shifted maximum values for $\operatorname{div}_{250}$, two possible reasons are assumed: First, the statistics depicted in Fig. 11 are based on the central position of the 24-h development phase (cf. Table 1, last row, third position). However, the strongest development typically occurs in the later stages of this 24-h period (cf., e.g., Table 1, positions four or five). If the statistics were redone to focus on these later stages of development, the maximum div 250 values would be closer to the cyclone core. In terms of $\theta_{\mathrm{e}}$, the largest values correspond to the area attributed to the warm sector of the cyclone, southeast of the core (as seen in the example in Fig. 2d). As expected (following Table 4), the results are also valid for each NAO phase (not shown). Thus, the enhanced number of extreme cyclones during the positive NAO phase can primarily be explained by the larger area with favourable growth conditions coherent with the cyclone tracks. This result is also valid for non-extreme cyclones, but differences/significances are smaller (not shown).

\section{Results based on GCM data}

In this section, the proposed methodology is applied to output from the ECHAM5 GCM. This will be done for both recent (1960-2000, historical forcing) and future (2060-2100, following the SRES A1B scenario) climate conditions, focussing primarily on extreme cyclones.

\subsection{North Atlantic Oscillation}

First, the NAO index for the GCM data is calculated in the same way as for the NCEP data. All three ensemble runs 

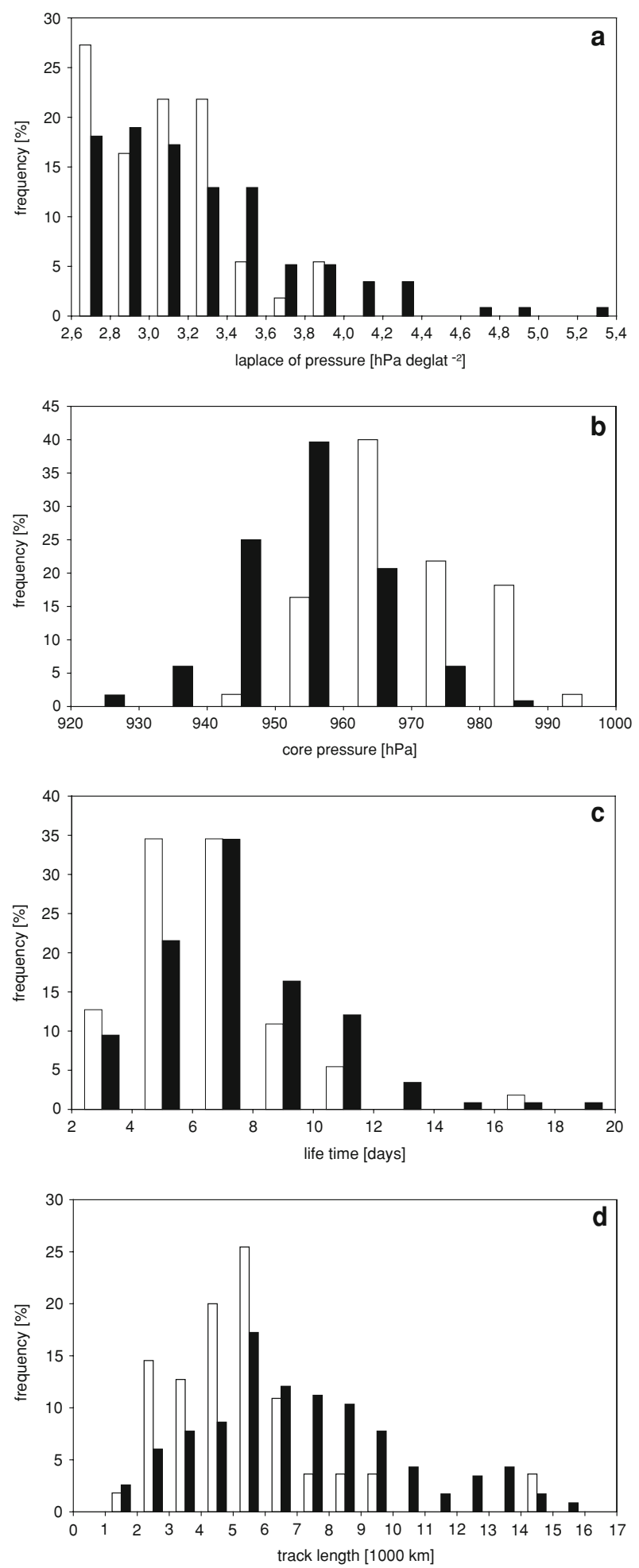

Fig. 8 Characteristics of extreme cyclones over the North Atlantic and Europe for NCEP (1958-1998) in terms of the NAO phase. a Maximum intensity $\left(\nabla^{2} p\right)\left(\mathrm{hPa}\right.$ deg.lat. $\left.{ }^{-2}\right)$, b minimum core pressure (hPa), c lifetime (days), d track length $(1,000 \mathrm{~km})$. Black bars correspond to $\mathrm{NAO}++$, white bars to $\mathrm{NAO}--$ are considered together for both present and future climate conditions (using concatenated series with 120 years each, in a total of 720 months). We prefer to process the data this way rather than considering the runs individually in order to provide a coherent basis for the subsequent investigations. However, the EOFs for the single runs are almost identical with those from the concatenated series. As with the NCEP data, the leading EOFs for present and future climate conditions represent the NAO pattern (Fig. 12). In detail, the southern centre of the dipole is fairly well represented in the model runs for present climate conditions, while the northern centre is located too far west. By the end of the twenty-first century, the southern centre shows weaker magnitude (while maintaining the same location), and the northern centre is "stretched" in comparison with 20C conditions. This could be a hint of a possible shift of the NAO poles under ACC, similar to the results by Ulbrich and Christoph (1999) based on the ECHAM4 GCM.

\subsection{Cyclone activity}

The mean values for track density and intensity for extreme cyclones for 20C are shown in Fig. 13. Their track density is well reproduced in terms of the spatial pattern, but the absolute values are reduced compared to NCEP (Fig. 4a vs. Fig. 13a). Accordingly, the mean cyclone intensity is also lower in the GCM (cf. Fig. 13b, 4b). The average jet ${ }_{250}$ is also shown in Fig. 13b, depicting a more zonal orientation than in NCEP (cf. Fig. 4b).

In terms of the ACC signal, the total number of cyclones is reduced by approximately $10 \%$ by the end of the twentyfirst century (Table 5 vs. Table 6, both first columns, last row). This is also valid for extreme cyclones over the whole domain (Table 5 vs. Table 6, both third columns, last row). However, a significant increase in cyclone track density is detected near the British Isles and over the North Sea (Fig. 14a), associated with an increase in cyclone intensity (Fig. 14b). Accordingly, the jet 250 shows significant enhanced values across the NA around $50^{\circ} \mathrm{N}$ (Fig. 14b). Interestingly, the results for non-extreme cyclones over the NA include only minor changes in cyclone intensity (not shown; cf. also P07, their Fig. 3b). Thus, the enhancement of cyclone intensity near the British Isles identified by P07 (their Fig. 3d) may be primarily attributed to extreme cyclones.

\subsection{Association with NAO and environmental factors}

For present day climate conditions, the relationship between the NAO phase, extreme cyclones and the environmental variables is largely similar to the observational results. As an 
Fig. 9 Composites of environmental factors contribution to the development of extreme cyclones in the $\mathrm{NAO}++$ phase. a 3-day running mean of Eady growth rate $400 \mathrm{hPa}\left(\right.$ day $\left.^{-1}\right)$, b jet stream $250 \mathrm{hPa}\left(\mathrm{m} \mathrm{s}^{-1}\right)$, c equivalent potential temperature $850 \mathrm{hPa}(\mathrm{K})$. Cyclones tracks displayed individually, maximum intensification phases marked with blue dots
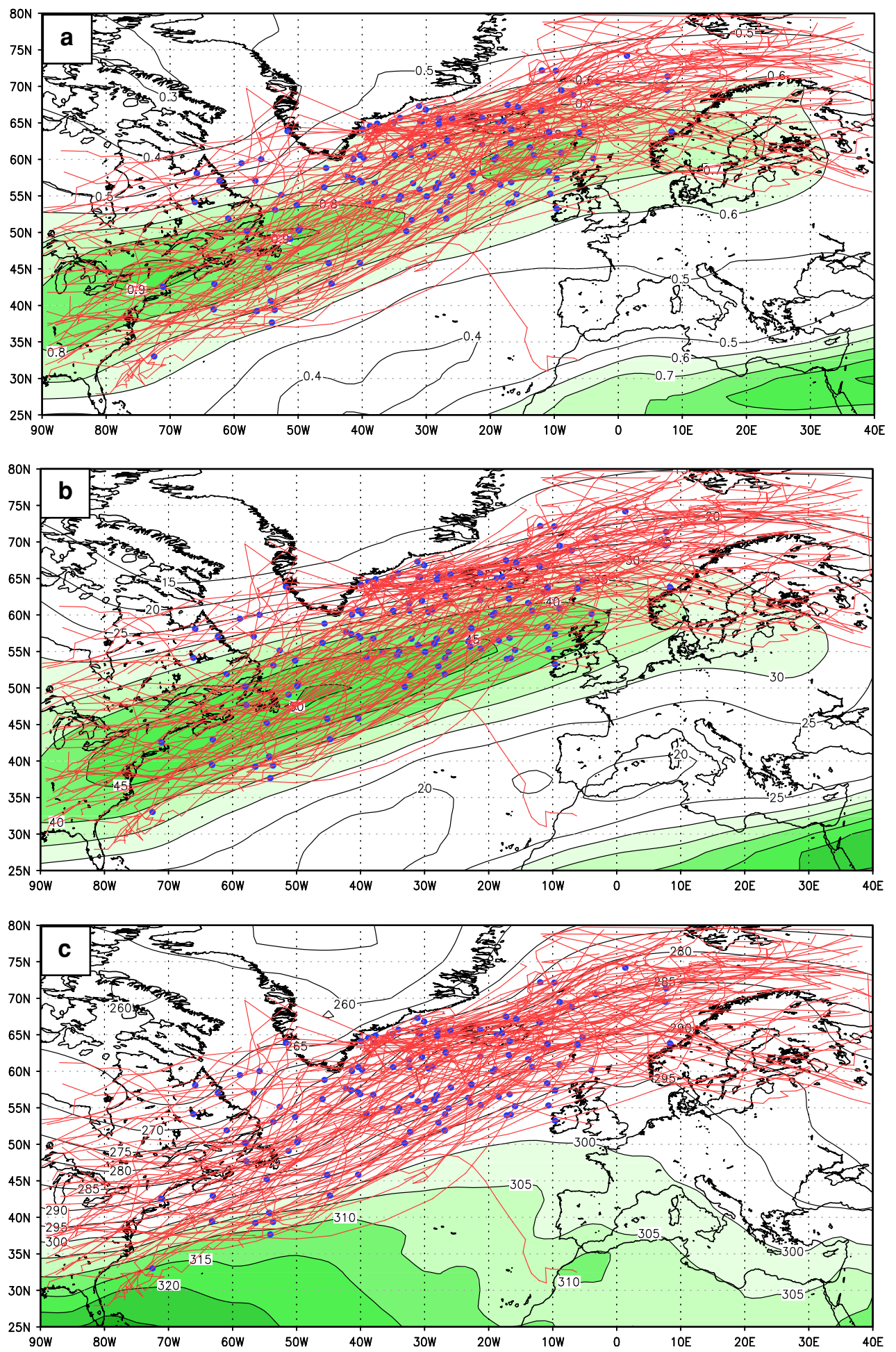

Under ACC conditions, the jet ${ }_{250}$ extends into Europe in both NAO phases, and the tracks of extreme cyclones are also apparently changed (Figs. 15b, 16b). A significant enhancement of jet $_{250}$ is detected from the central NA into the North and Baltic Seas under ACC for NAO++ (Fig. 15c), while for the NAO-- phase the jet is intensified around $40^{\circ} \mathrm{N}-45^{\circ} \mathrm{N}$ (Fig. 16c). On the other hand, the 
Fig. 10 Composites of environmental factors contribution to the development of extreme cyclones in the NAO-- phase. a 3-day running mean of Eady growth rate $400 \mathrm{hPa}\left(\right.$ day $\left.^{-1}\right)$, b jet stream $250 \mathrm{hPa}\left(\mathrm{m} \mathrm{s}^{-1}\right)$, c equivalent potential temperature $850 \mathrm{hPa}(\mathrm{K})$. Cyclones tracks displayed individually, maximum intensification phases marked with blue dots
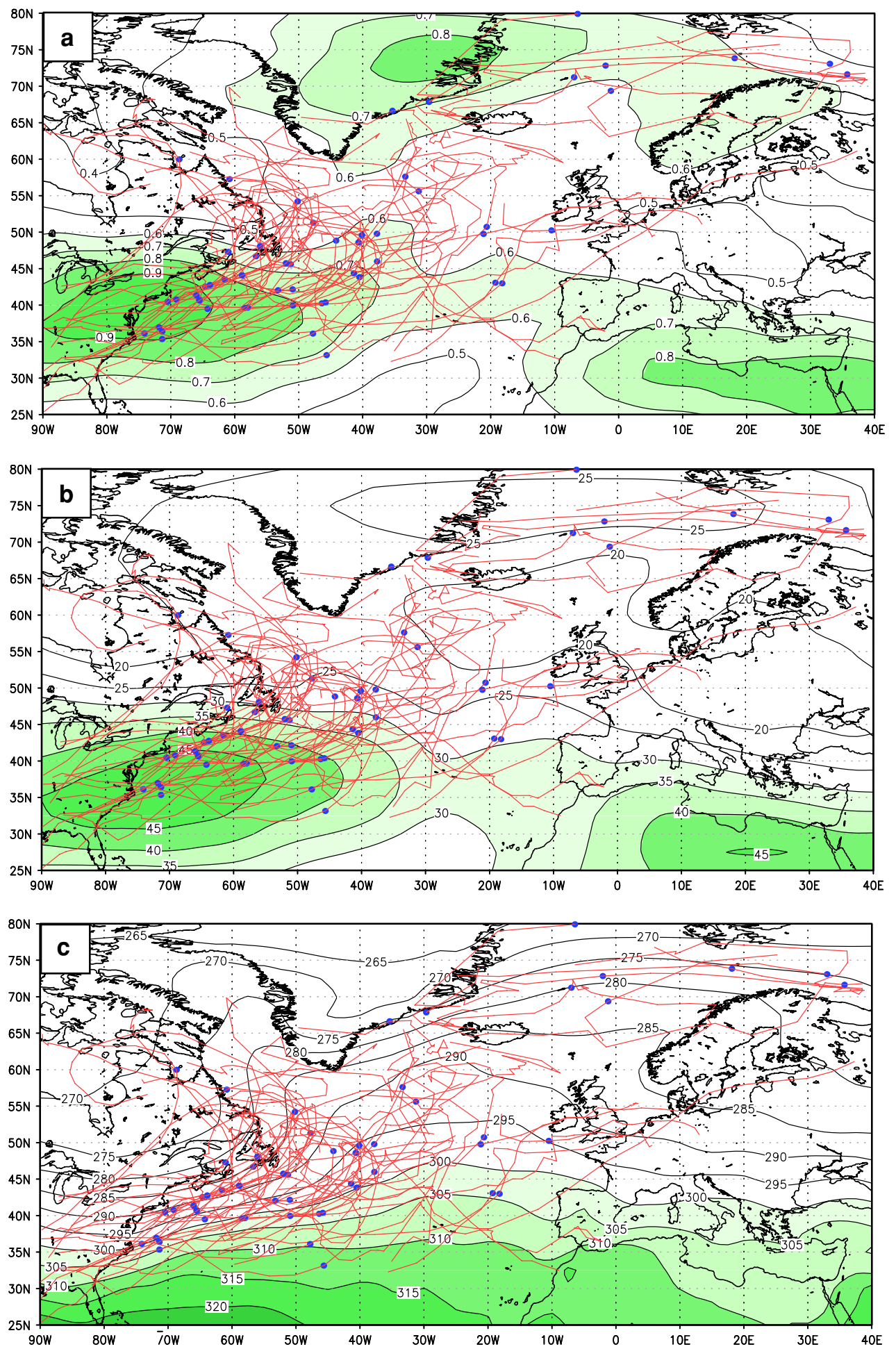

changes in track density of extreme cyclones remain largely non-significant (unlike the results for all NAO phases together, cf. Fig. 14b). This is due to the comparatively small numbers in these two NAO phases (cf. Tables 5, 6). For example, the values over and west of the British Isles (around $45^{\circ} \mathrm{N}-50^{\circ} \mathrm{N}$ ) have a significance level around 0.85 in the NAO-- phase. Still, all NAO phases are found to contribute to the enhancement of extreme cyclones affecting Europe under ACC.

Next, we have analysed the percentage of exceedance of the four environmental variables near the extreme cyclone centres for the ECHAM5 cyclones, similar to results shown for NCEP in Fig. 11. The changes between present and future climate conditions are shown in Fig. 17: a 
Table 4 Extreme value statistics for NCEP (1958-1998) per NAO phase

\begin{tabular}{|c|c|c|c|c|c|c|c|c|}
\hline \multirow[t]{2}{*}{ Phase } & \multicolumn{4}{|c|}{ Non-extreme cyclones } & \multicolumn{4}{|c|}{ Extreme cyclones } \\
\hline & $\sigma_{400}$ & jet $_{250}$ & $\operatorname{div}_{250}$ & $\theta_{\mathrm{e}}$ & $\sigma_{400}$ & jet $_{250}$ & $\operatorname{div}_{250}$ & $\theta_{\mathrm{e}}$ \\
\hline NAO-- & 32 & 29 & 82 & 46 & 49 & 40 & 96 & 62 \\
\hline NAO- & 33 & 28 & 81 & 46 & 47 & 40 & 98 & 61 \\
\hline NAO 0 & 32 & 30 & 81 & 44 & 47 & 46 & 97 & 68 \\
\hline $\mathrm{NAO}+$ & 27 & 31 & 79 & 41 & 45 & 47 & 94 & 64 \\
\hline $\mathrm{NAO}++$ & 28 & 33 & 76 & 40 & 44 & 66 & 95 & 71 \\
\hline NAOall & 31 & 30 & 81 & 44 & 46 & 47 & 96 & 66 \\
\hline
\end{tabular}

Frequency of extreme values ( $>95$ th percentile) within a radius of $500 \mathrm{~km}$ around the cyclone core $(\%)$ for Eady growth rate $\left(\sigma_{400}\right)$, upper air jet stream (jet 250$)$, divergence $\left(\operatorname{div}_{250}\right)$, equivalent-potential temperature $\left(\theta_{\mathrm{e}}\right)$. The last row corresponds to all NAO phases together significant increase of the percentage of extreme values is found for all variables, particularly for $\sigma_{400}$ (Fig. 17a), with an increase of over $+2 \%$ within the $500 \mathrm{~km}$ radius. If the percentiles for present climate conditions are considered, the changes are even larger, particularly for $\theta_{\mathrm{e}}$, reaching $+21 \%$ within the $500 \mathrm{~km}$ radius (not shown). The mean frequencies of extreme cyclones versus non-extreme cyclones are further analysed for the different NAO phases. The results (Table 5) are similar to those obtained for NCEP (cf. Table 3), and the ACC signal is comparatively small (cf. Table 6). The analysis of the frequency of extreme values of environmental variables associated with ECHAM5 cyclones for present (Table 7) and future (Table 8) leads to more differentiated conclusions: For non-extreme cyclones, values remain similar between the
Fig. 11 Composite for all extreme cyclones in terms of the environmental variables centred on the cyclone location for central position $\left[40^{\circ} \times 40^{\circ}\right.$ box] during the intensification phase for NCEP. Shown are the frequencies of exceedance of the 95th percentile for each grid point $(\%)$. a Eady growth rate $400 \mathrm{hPa}, \mathbf{b}$ jet $250 \mathrm{hPa}$, c divergence $250 \mathrm{hPa}$, d equivalent potential temperature $850 \mathrm{hPa}$. The circles in a-d correspond to the 500 and $1,000 \mathrm{~km}$ radius for $55^{\circ} \mathrm{N}$; the values within the $500 \mathrm{~km}$ radius are considered for the statistics in Table 4. Significance values computed with bootstrap method denoted in colour, 95th (99th) confidence levels are shown in orange (red). For further details see text
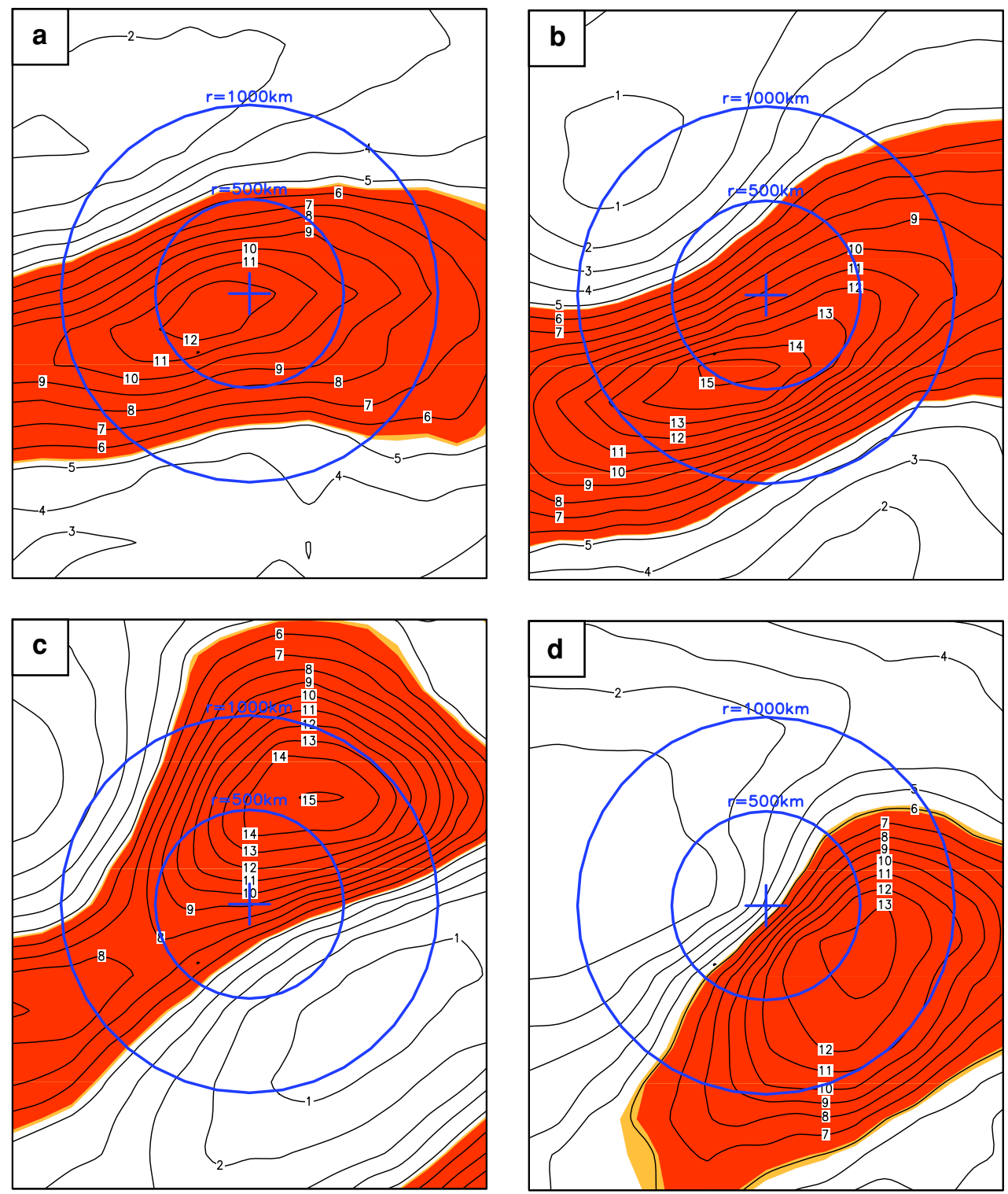
Fig. 12 NAO definition for GCM. Leading MSLP EOF for North Atlantic/Europe $\left(90^{\circ} \mathrm{W}-\right.$ $50^{\circ} \mathrm{E} ; 20^{\circ} \mathrm{N}-80^{\circ} \mathrm{N}$ ) using latitude weighting for ECHAM5 data. a $20 \mathrm{C}$ ensemble average (1960-2100), b A1B ensemble average (2060-2100).

Explained variances are a $35.41 \%$, b $38.30 \%$. Period is October-March
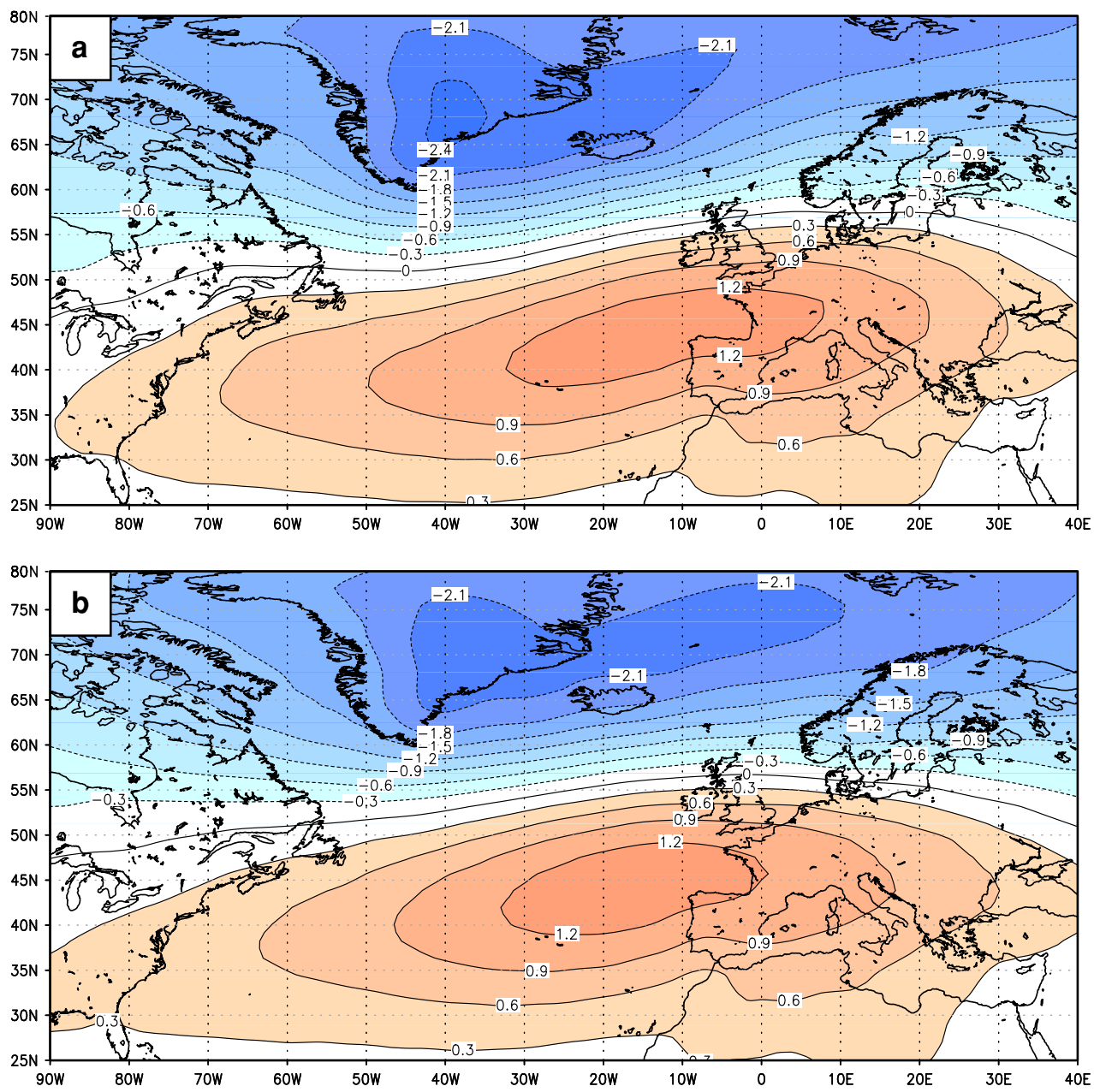

two periods; for extreme cyclones, values are enhanced, particularly for $\sigma_{400}$ and $\theta_{\mathrm{e}}$, where the frequency of extreme values raises to 56 and $76 \%$, respectively, for all NAO phases. The percentiles for the correspondent periods were considered for these statistics (e.g., 2060-2100 percentiles for Table 8).

More importantly, the average $\theta_{\mathrm{e}}$ value raise from $299.7 \mathrm{~K}$ in $20 \mathrm{C}$ to $308.1 \mathrm{~K}(+8.4 \mathrm{~K}$; for comparison, the value for non-extreme cyclones is $+6 \mathrm{~K})$. Considering the individual NAO phases, $\theta_{\mathrm{e}}$ changes range from $+11.5 \mathrm{~K}$ for $\mathrm{NAO}--$ to $6 \mathrm{~K}$ for $\mathrm{NAO}++$. If the present climate 95 th percentile values for $\theta_{\mathrm{e}}$ would be considered, the frequency of extreme values for A1B raises up to almost $100 \%$. Changes in $\theta_{\mathrm{e}}$ for Fig. $17 \mathrm{~d}$ and Tables 7 and 8 are partially associated with the southern shift of the cyclone tracks close to Europe (as seen in Fig. 14a). Nevertheless, the relationships between the environmental factors and cyclone development for present climate conditions remain largely valid under ACC, possibly with the exception of $\theta_{\mathrm{e}}$, which could play a more important role in cyclone intensification under future climate conditions.

\subsection{Storms developing close to the European continent}

Storms which undergo a strong intensification phase close to Europe may be a major challenge for forecasters (cf., e.g., Ulbrich et al. 2001). One of the factors contributing for such a 'late' development is the extension of the jet stream (and hence of the associated barocline zone) over the eastern NA/Western Europe. Hence, additional composite studies are performed for extreme systems fulfilling the following conditions:

- intensification phase $(24 \mathrm{~h})$ ends close to or within Europe $\left(15^{\circ} \mathrm{W}-20^{\circ} \mathrm{E}, 45^{\circ} \mathrm{N}-60^{\circ} \mathrm{N}\right)$

- intensity values reach at least $2.5 \mathrm{hPa}$ deg.lat. ${ }^{-2}$

- intensification rate is at least $1.0 \mathrm{hPa}$ deg.lat. ${ }^{-2}$ for $24 \mathrm{~h}$

The second and third conditions must be fulfilled within the defined area. For the NCEP period, a total of 62 systems (cf. Table 9) fulfil these conditions and are shown in Fig. 18a together with a composite of the jet 250 . The distribution of these storms is slightly skewed to positive NAO phases (Table 9, first column). The central position 
Fig. 13 Characteristics of extreme cyclones over the North Atlantic and Europe for ECHAM5 ensemble average with present climate conditions (20C, 1960-2000). a Track density (cyclone days/winter), $\mathbf{b}$ mean $\nabla^{2} p$ (hPa deg.lat. $\left.{ }^{-2}\right)$. Green lines in $\mathbf{b}$ correspond to mean jet stream $250 \mathrm{hPa}\left(\mathrm{m} \mathrm{s}^{-}\right.$ 1)
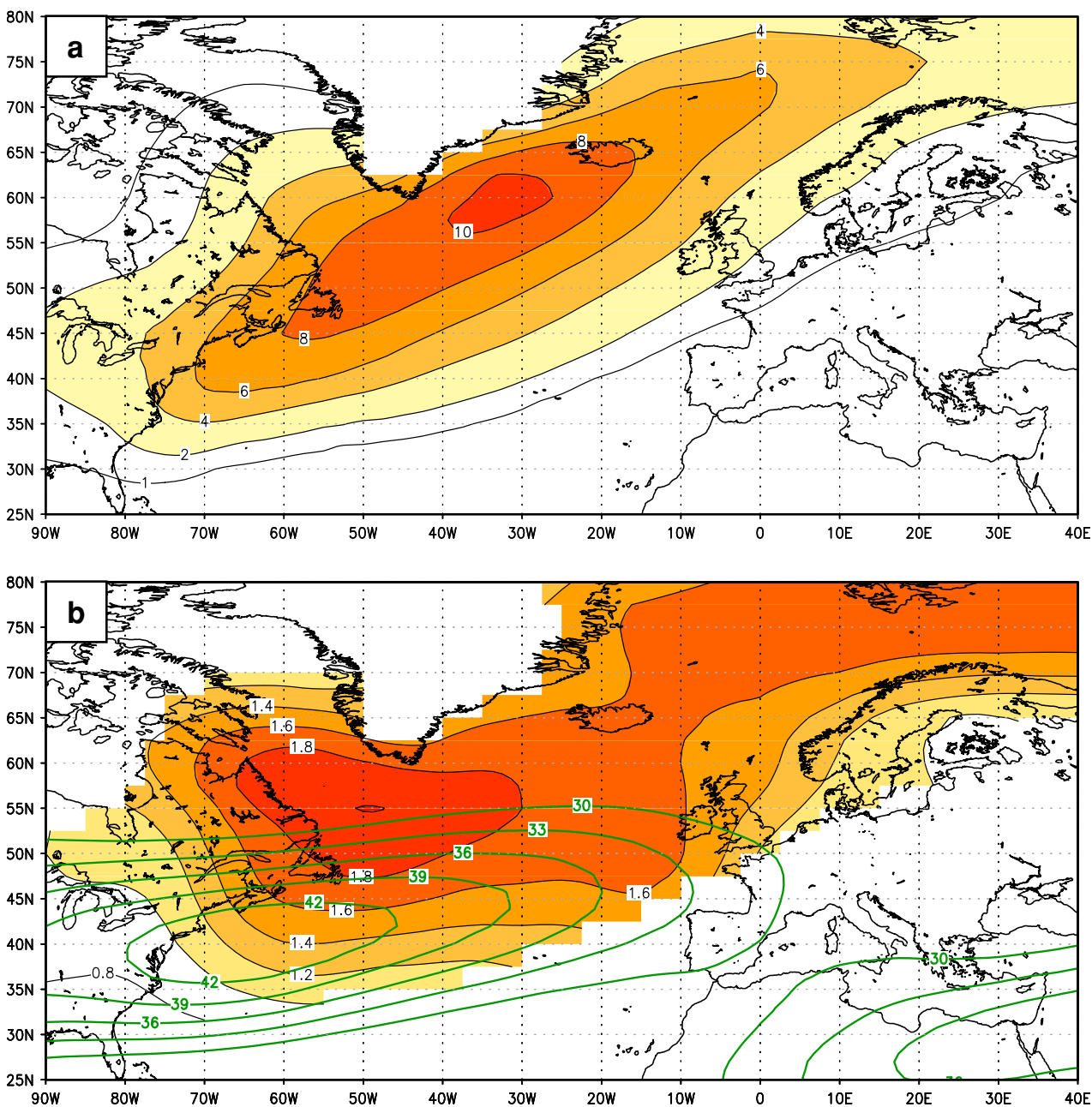

Table 5 Average statistics for ECHAM5-20C ensemble (19602000)

\begin{tabular}{lllll}
\hline Phase & ALL & N-EXT & EXT & QUOTIENT \\
\hline NAO-- & $7.2 \%$ & $7.5 \%$ & $4.4 \%$ & $6.1 \%$ \\
NAO- & $24.0 \%$ & $24.5 \%$ & $19.6 \%$ & $8.2 \%$ \\
NAO 0 & $37.7 \%$ & $37.7 \%$ & $37.8 \%$ & $10.0 \%$ \\
NAO+ & $25.3 \%$ & $24.7 \%$ & $30.4 \%$ & $12.0 \%$ \\
NAO++ & $5.8 \%$ & $5.6 \%$ & $7.8 \%$ & $13.4 \%$ \\
Tracks total & 38,153 & 34,343 & 3,810 &
\end{tabular}

ALL, percentage of all cyclones per NAO phase; N-EXT, percentage of non-extreme cyclones per NAO phase; EXT, percentage of extreme cyclones per NAO phase; QUOTIENT, quotient extreme versus all cyclones per NAO phase

The values are given as a percentage of the total number of cyclones (cf. last row). The percentages of each column sum to $100 \%$. Last row: total number of cyclone tracks in the data set (120 winters)

of the strengthening phase is biased towards the western boundary of the considered box (Fig. 18a, blue dots). In the GCM, the number of systems is on ensemble average
Table 6 Average statistics for ECHAM5-A1B ensemble (20602100)

\begin{tabular}{lllll}
\hline Phase & ALL & N-EXT & EXT & QUOTIENT \\
\hline NAO-- & $7.4 \%$ & $7.7 \%$ & $5.2 \%$ & $7.0 \%$ \\
NAO- & $23.0 \%$ & $23.4 \%$ & $19.3 \%$ & $8.4 \%$ \\
NAO 0 & $37.8 \%$ & $37.8 \%$ & $38.2 \%$ & $10.1 \%$ \\
NAO+ & $26.5 \%$ & $26.1 \%$ & $29.9 \%$ & $11.3 \%$ \\
NAO++ & $5.3 \%$ & $5.0 \%$ & $7.4 \%$ & $13.9 \%$ \\
Tracks total & 34,174 & 30,761 & 3,413 &
\end{tabular}

ALL, percentage of all cyclones per NAO phase; N-EXT, percentage of non-extreme cyclones per NAO phase; EXT, percentage of extreme cyclones per NAO phase; QUOTIENT, quotient extreme versus all cyclones per NAO phase

The values are given as a percentage of the total number of cyclones (cf. last row). The percentages of each column sum to $100 \%$. Last row: total number of cyclone tracks in the data set (120 winters)

42 for current climate conditions (Fig. 18b) and 56 for the end of the twenty-first century (Fig. 18c). This small set of data corresponds roughly to $3-5 \%$ of all extreme 
Fig. 14 Characteristics of extreme cyclones over the North Atlantic and Europe for ECHAM5 ensemble average for A1B minus 20C (2060-2100 vs. 1960-2000). a Track density (cyclone days/winter), b mean $\nabla^{2} p\left(\right.$ hPa deg.lat. $\left.{ }^{-2}\right)$. Areas with significant differences (95th and 99th confidence levels) are in colour ( $T$ test on winter basis). Green lines in b correspond to changes in mean jet stream $250 \mathrm{hPa}\left(\mathrm{m} \mathrm{s}^{-1}\right)$ (light green negative, dark green positive), areas with significant differences (95th confidence levels, $T$ test on winter basis) are marked with green dots
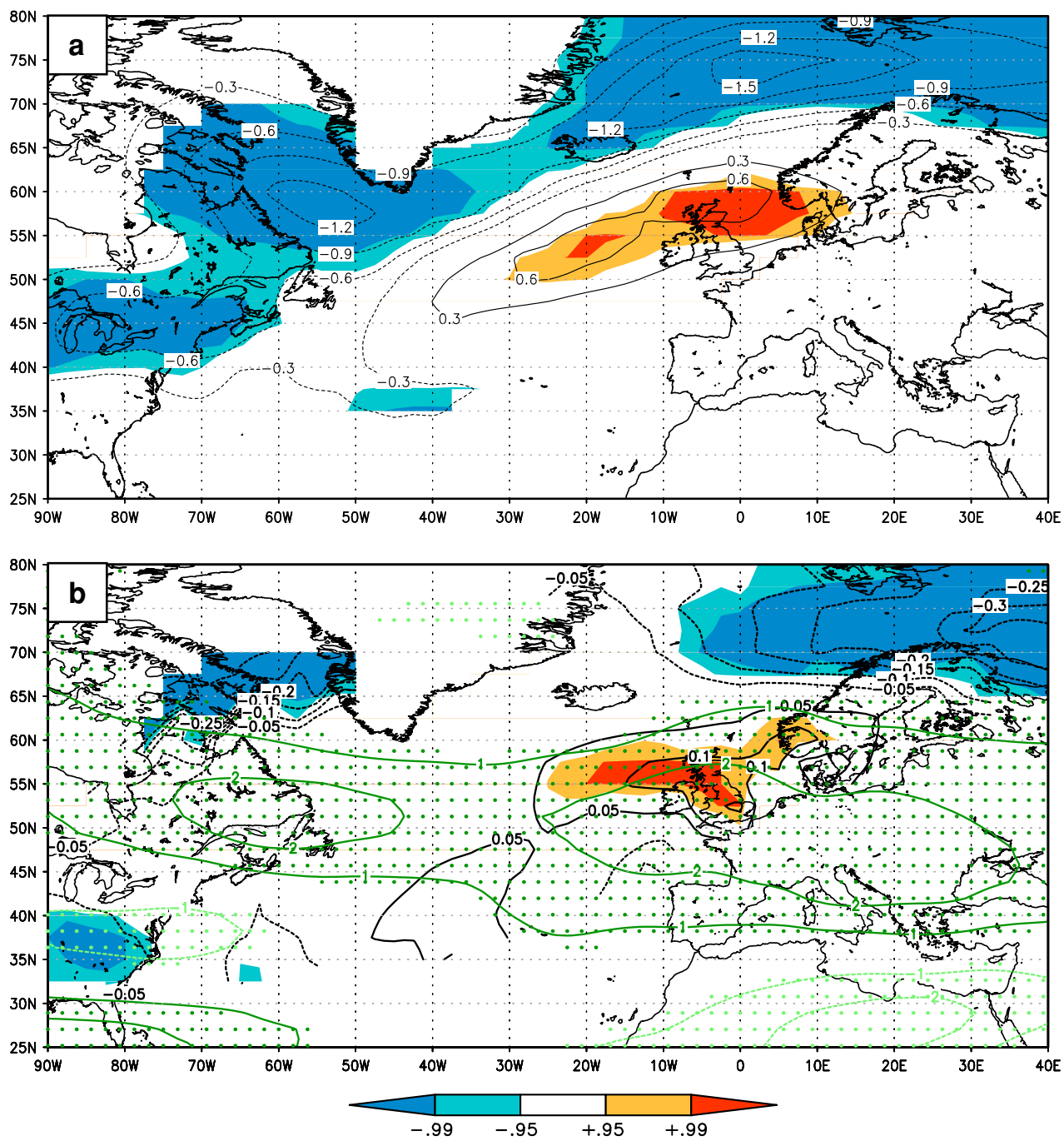

storms in the NCEP and GCM, typically includes very intense storms. Figure 19 shows the difference in the jet $_{250}$ and cyclone track density between panels (c) and (b), indicating a local intensification of the jet ${ }_{250}$ (particularly over the North Sea) and an enhanced frequency of very extreme storms intensifying close to Europe. These changes occur particularly during the $\mathrm{NAO}--$ phase, and to a lesser extend with the NAO 0 and NAO+ phases (Table 9, cf. columns 2 and 3). The detected enhanced frequency of explosive developments close to Europe potentially implies an increased risk of high impact weather over Central Europe, as the gust fields associated with extratropical storms are characteristically located several hundred kilometres south of the cyclone core, typically along the cold front (cf. Ulbrich et al. 2001; Fink et al. 2008). Such an assessment is in agreement with the results of Pinto et al. (2007a), which found an enhanced frequency of windstorms over Western Europe in these simulations.

\section{Discussion and conclusions}

In this work, we analyse the occurrence of extreme cyclones (i.e., systems which underwent a stronger intensification) and their relationship to the NAO phase and to the dominating environmental variables controlling their intensification. Beyond the well-known fact that the NAO is affecting the location and orientation of the cyclone tracks, producing a north-easterly extension of the storm tracks in positive NAO phases, its influence on the occurrence of extreme systems over the NA is quantified. These cyclones occur more (less) frequently during strong positive (negative) NAO phases (14.9 vs. 5.4\% of all cyclones, cf. Table 3). Moreover, extreme cyclones in the NAO++ phase have typically higher intensities (Fig. 8a), deeper cores (Fig. 8b), longer lifetimes (Fig. 8c) and longer track lengths (Fig. 8d). These results suggest that extreme cyclones in the NAO++ phase typically have a more intense/longer intensification phase (see also below). 
Fig. 15 Composite of cyclone tracks and jet stream $250 \mathrm{hPa}$ for extreme cyclones for the $\mathrm{NAO}++$ phase. a ECHAM5 20C ensemble average (1960 2000) $\left(\mathrm{m} \mathrm{s}^{-1}\right)$, b ECHAM5

A1B ensemble average (20602100) $\left(\mathrm{m} \mathrm{s}^{-1}\right)$. For these panels, cyclone tracks displayed individually, maximum intensification phases marked with blue dots, $\mathbf{c}$ differences $\mathbf{b}$ versus a for cyclone track density (cyclone days/winter) and jet stream $250 \mathrm{hPa}\left(\mathrm{m} \mathrm{s}^{-1}\right)$. Black lines correspond to changes for cyclone track density, areas with significant differences (95th and 99th confidence levels) are in colour ( $T$ test on winter basis). Green lines correspond to changes for jet stream $250 \mathrm{hPa}$ (light green negative, dark green positive), areas with significant differences (95th confidence levels, $T$ test on winter basis) are marked with green dots
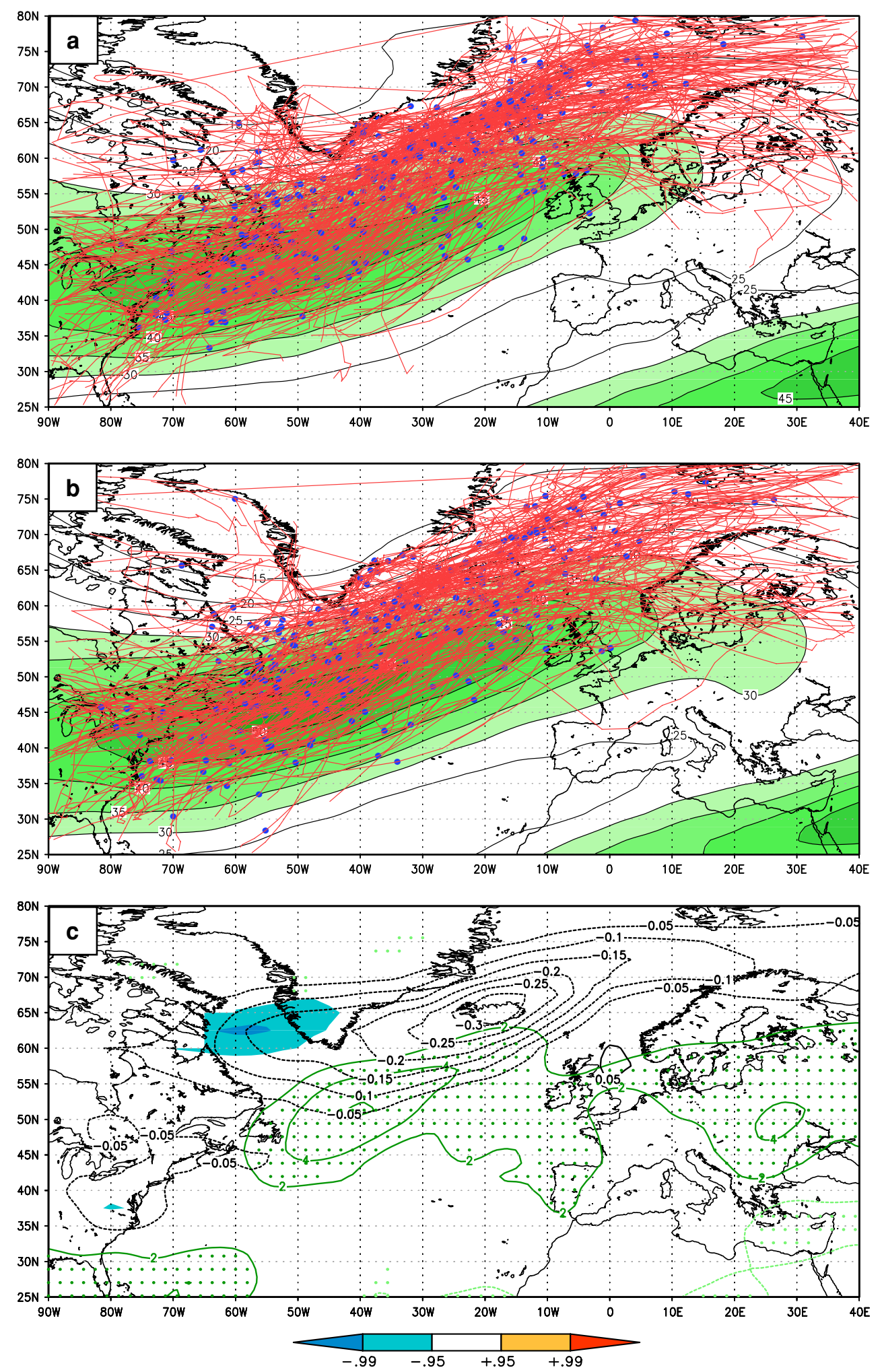

Hence, a relationship between the NAO phase and the occurrence of extreme cyclones is given.

Further, the cyclones' intensification is closely linked to the occurrence of extreme values in the environmental growth factors, as their extreme values are more frequently found for extreme cyclones (cf. Table 4). Whereas the variables jet ${ }_{250}$ and $\sigma_{400}$ show a clear connection to the intensification of extreme cyclones on a regional perspective (Figs. 9, 10), the relevance of $\operatorname{div}_{250}$ and $\theta_{\mathrm{e}}$ is better revealed when considering a Lagrangian perspective (Fig. 11). 
Fig. 16 Composite of cyclone tracks and jet stream $250 \mathrm{hPa}$ for extreme cyclones for the NAO-- phase. a ECHAM5 20C ensemble average (1960 2000) $\left(\mathrm{m} \mathrm{s}^{-1}\right)$, b ECHAM5

A1B ensemble average (20602100) $\left(\mathrm{m} \mathrm{s}^{-1}\right)$. For these panels, cyclone tracks displayed individually, maximum intensification phases marked with blue dots. c Differences b versus a for cyclone track density (cyclone days/winter) and jet stream $250 \mathrm{hPa}\left(\mathrm{m} \mathrm{s}^{-1}\right)$. Black lines correspond to changes for cyclone track density, areas with significant differences (95th and 99th confidence levels) are in colour ( $T$ test on winter basis). Green lines correspond to changes for jet stream $250 \mathrm{hPa}$ (light green negative, dark green positive), areas with significant differences (95th confidence levels, $T$ test on winter basis) are marked with green dots
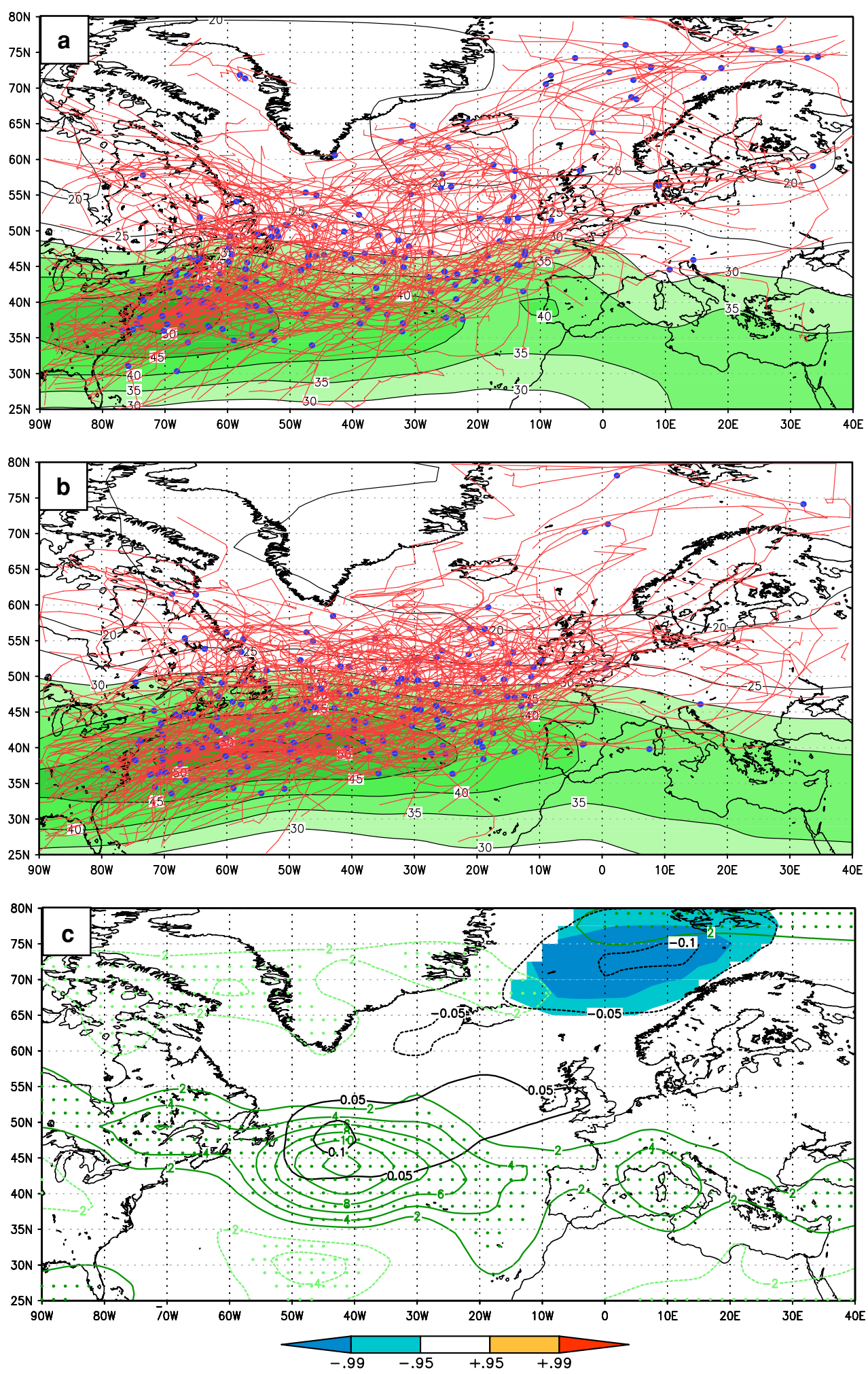

Reasons for these differences are associated with the different characteristics of these variables in terms of average fields. The enhanced numbers of extreme cyclones in positive NAO phases can be primarily explained by the large and spatially coherent area of favourable growth conditions visible in the respective NAO composite, while the region of favourable growth conditions is smaller and less stratified with respect to the corresponding cyclone tracks in negative NAO phases (Figs. 9, 10). This assessment is consistent with the above result of extreme cyclones being more 
Fig. 17 Composite for all extreme cyclones in terms of the environmental variables centred on the cyclone location for central position $\left[40^{\circ} \times 40^{\circ}\right.$ box] during the intensification phase for ECHAM5. Shown are the changes in the frequency of exceedance of the 95th percentile for A1B minus 20C ensemble average (2060-2100 vs. 1960-2000) for each grid point. a Eady growth rate $400 \mathrm{hPa}, \mathbf{b}$ jet $250 \mathrm{hPa}, \mathbf{c}$ divergence $250 \mathrm{hPa}, \mathbf{d}$ equivalent potential temperature $850 \mathrm{hPa}$. The circles in a-d correspond to the 500 and $1,000 \mathrm{~km}$ radius for $55^{\circ} \mathrm{N}$. Areas with significant differences (95th and 99th confidence levels) are in colour ( $T$ test on winter basis)
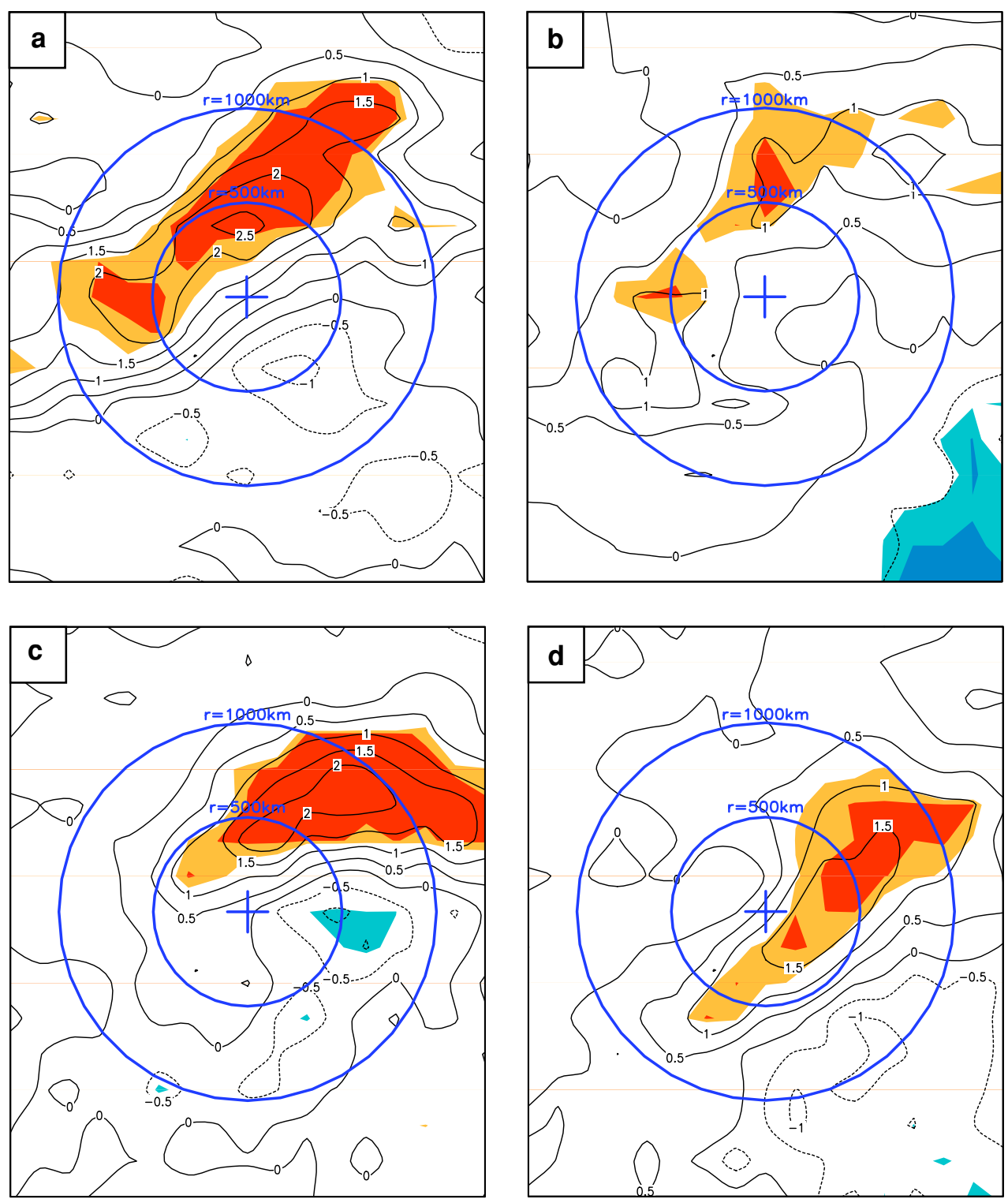

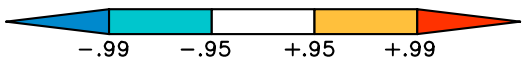

intense, deeper, having a longer lifetime and a track length in the $\mathrm{NAO}++$ phase than in the $\mathrm{NAO}--$ phase.

The main cyclogenetic area for extreme cyclones off the east coast of the US (cf. Fig. 4c) was also identified by Gray and Dacre (2006) as main source region of cyclones of type B following the threefold classification scheme of extratropical cyclogenesis by Deveson et al. (2002), an extension of the classification by Petterssen and Smebye (1971). This type B of cyclone development is predominantly upper-level forced. This agrees with our choice of variables to analyse cyclone development (upper level jet ${ }_{250}, \sigma_{400}$ and $\operatorname{div}_{250}$ ).

Next, we analysed the impact of ACC in the relationships found between extreme cyclones, NAO phase and environmental variables. Similar relationships between extreme cyclones and NAO phase are found for ECHAM5 cyclones under recent climate conditions. The ACC for the A1B scenario reveals a reduced total number of cyclones (ca. $10 \%$ ) by the end of the twenty-first century (Tables 5, 6). Similar results have been detected for other GCMs (e.g., Leckebusch et al. 2006; Pinto et al. 2006). We assume that these changes are related to the reduced temperature gradient in the lower troposphere-and hence reduced lowlevel baroclinicity (not shown) and a reduced necessity of latitudinal mass/energy transport on average (cf. Meehl et al. 2007; their Fig. 10.7). For extreme cyclones, both an enhancement of track density and intensity is detected near the British Isles (Fig. 8). Similar results were obtained by Bengtsson et al. (2006) for the same GCM simulations 
Table 7 Extreme value statistics for ECHAM5-20C ensemble average (1960-2000) per NAO phase

\begin{tabular}{|c|c|c|c|c|c|c|c|c|}
\hline \multirow[t]{2}{*}{ Phase } & \multicolumn{4}{|c|}{ Non-extreme cyclones } & \multicolumn{4}{|c|}{ Extreme cyclones } \\
\hline & $\sigma_{400}$ & jet $_{250}$ & $\operatorname{div}_{250}$ & $\theta_{\mathrm{e}}$ & $\sigma_{400}$ & jet $_{250}$ & $\operatorname{div}_{250}$ & $\theta_{\mathrm{e}}$ \\
\hline NAO-- & 37 & 30 & 79 & 45 & 56 & 40 & 98 & 70 \\
\hline NAO- & 40 & 34 & 80 & 49 & 52 & 44 & 95 & 68 \\
\hline NAO 0 & 38 & 35 & 80 & 49 & 53 & 50 & 97 & 71 \\
\hline $\mathrm{NAO}+$ & 35 & 40 & 80 & 47 & 51 & 59 & 97 & 74 \\
\hline $\mathrm{NAO}++$ & 30 & 38 & 76 & 44 & 32 & 57 & 98 & 65 \\
\hline NAOall & 37 & 36 & 80 & 48 & 51 & 50 & 97 & 71 \\
\hline
\end{tabular}

Frequency of extreme values ( $>95$ th percentile) within a radius of $500 \mathrm{~km}$ around the cyclone core $(\%)$ for Eady growth rate $\left(\sigma_{400}\right)$, upper air jet stream $\left(\right.$ jet $\left._{250}\right)$, divergence $\left(\operatorname{div}_{250}\right)$, equivalent-potential temperature $\left(\theta_{\mathrm{e}}\right)$

The last row corresponds to all NAO phases together

Table 8 Extreme value statistics for ECHAM5-A1B ensemble average (2060-2100) per NAO phase

\begin{tabular}{|c|c|c|c|c|c|c|c|c|}
\hline \multirow[t]{2}{*}{ Phase: } & \multicolumn{4}{|c|}{ Non-extreme cyclones } & \multicolumn{4}{|c|}{ Extreme cyclones } \\
\hline & $\sigma_{400}$ & jet $_{250}$ & $\operatorname{div}_{250}$ & $\theta_{\mathrm{e}}$ & $\sigma_{400}$ & jet $_{250}$ & $\operatorname{div}_{250}$ & $\theta_{\mathrm{e}}$ \\
\hline NAO-- & 39 & 32 & 83 & 52 & 55 & 51 & 100 & 68 \\
\hline NAO- & 41 & 33 & 83 & 50 & 57 & 52 & 99 & 76 \\
\hline NAO 0 & 38 & 37 & 82 & 49 & 58 & 50 & 100 & 79 \\
\hline $\mathrm{NAO}+$ & 35 & 37 & 78 & 45 & 54 & 57 & 98 & 74 \\
\hline $\mathrm{NAO}++$ & 27 & 38 & 75 & 44 & 49 & 63 & 99 & 74 \\
\hline NAOall & 37 & 36 & 81 & 48 & 56 & 53 & 99 & 76 \\
\hline
\end{tabular}

Frequency of extreme values ( $>95$ th percentile) within a radius of $500 \mathrm{~km}$ around the cyclone core $(\%)$ for Eady growth rate $\left(\sigma_{400}\right)$, upper air jet stream $\left(\right.$ jet $\left._{250}\right)$, divergence $\left(\operatorname{div}_{250}\right)$, equivalent-potential temperature $\left(\theta_{\mathrm{e}}\right)$

The last row corresponds to all NAO phases together

Table 9 Number of cyclones featuring a very strong intensification near the British Isles

\begin{tabular}{llll}
\hline Phase & NCEP & ECHAM5-20C & ECHAM5-A1B \\
\hline NAO-- & $5(2.670)$ & $4.7(3.021)$ & $4.3(2.941)$ \\
NAO- & $9(2.832)$ & $6.7(2.851)$ & $13.7(2.948)$ \\
NAO 0 & $26(2.853)$ & $19.0(2.864)$ & $22.3(2.913)$ \\
NAO+ & $14(3.034)$ & $9.7(2.831)$ & $13.0(2.973)$ \\
NAO++ & $8(2.931)$ & $2.3(2.927)$ & $2.3(2.856)$ \\
NAOall & $62(2.886)$ & $42.3(2.875)$ & $55.7(2.935)$ \\
\hline
\end{tabular}

Total numbers per NAO phase for NCEP (1958-1998), ECHAM520C (1960-2000) and ECHAM5-A1B (2060-2100). For ECHAM5, ensemble averages are considered. The correspondent average $\nabla^{2} p$ values ( $\mathrm{hPa}$ deg. lat. ${ }^{-2}$ ) are given in brackets

The last row corresponds to all NAO phases together

using a different methodology and by Watterson (2006) using two CSIRO GCMs. Indeed, many GCMs show increased synoptic activity under ACC forcing over the eastern NA (e.g., Ulbrich et al. 2008b). Regarding other
SRES scenarios, $\mathrm{P} 07$ analysed the simulations considered here plus $\mathrm{A} 2$ and $\mathrm{B} 1$ ensembles, and the main conclusion was that the changes on cyclone activity were largely dependent on the intensity of the forcing. Hence, for the scenario A2 (B1) larger (smaller) changes should be expected in comparison to the A1B scenario presented here.

For the environmental variables, the results for present climate conditions (20C) are also similar to those obtained for NCEP data. Further, results suggest that the relationship between cyclone development and the environmental factors may remain largely similar under ACC. However, the percentage of cyclones featuring extreme values near the cyclone core during the maximum intensification phase for the A1B scenario increases significantly (Fig. 17), in particular for $\sigma_{400}$ and $\theta_{\mathrm{e}}$. In terms of absolute values, the largest increases for extreme cyclones are found for $\theta_{\mathrm{e}}$ : $+8.4 \mathrm{~K}$ on average within the $500 \mathrm{~km}$ radius. If the percentiles for the present climate conditions are considered, the absolute and relative change is even larger for $\theta_{\mathrm{e}}$. Thus, all environmental variables and in particular $\theta_{\mathrm{e}}$ seem to play a more important role in the intensification of extreme cyclones in future climate conditions. This assessment is in agreement with results by Watterson (2006), which suggested that latent heat during storms increases under ACC, as could be expected from the increased moisture capacity of the warmer atmosphere. However, detailed modelling studies would be needed to quantify the individual contributions of $\theta_{\mathrm{e}}, \mathrm{jet}_{250}, \sigma_{400}$ and $\operatorname{div}_{250}$ to intensify cyclones. Along the same lines, further variables influencing cyclone intensification, like upper-tropospheric vorticity advection (e.g., Sanders 1986), low static stability (e.g., Nuss and Anthes 1987), sea surface temperature gradients (e.g., MacDonald and Reiter 1988) and also dry intrusions (e.g., Young and Grahame 1999) should be considered in future investigations.

We have determined the NAO patterns individually for the control and scenario period, finding a small shift eastward of the pattern with increasing ACC, particularly for the northern pole (similar results have been obtained by Ulbrich and Christoph 1999). Determining the NAO from the two combined periods, an increasing NAO index is found in agreement with P07. In fact, an increasing NAO index under ACC is a common feature of several GCMs analysed by Osborn (2004). Relating the changes in the NAO to the eastward shift detected for extreme cyclones, we think the latter to be possibly rather associated with the geographical shift of the NAO poles than with the shift of the index itself to a more positive phase, as from index changes alone north-south shifts of activity could rather be expected. Thus, other factors surely play a role in the changes of cyclone activity, e.g., the reduced frequency of blocking situations over the whole North Hemisphere, leading to a more zonal flow (cf. P07; their Figs. 7, 8). 
Fig. 18 Composites of cyclones undergoing very strong development near the British Isles $\left(15^{\circ} \mathrm{W}-20^{\circ} \mathrm{E}\right.$, $45^{\circ} \mathrm{N}-60^{\circ} \mathrm{N}$ ) and associated jet stream $250 \mathrm{hPa}$. a Cyclones tracks NCEP (1958-1998, 62 tracks), green field corresponds to the jet stream $250 \mathrm{hPa}\left(\mathrm{m} \mathrm{s}^{-}\right.$ ${ }^{1}$ ), b same as a but for ECHAM5 20C ensemble (1960-2000, 127 tracks), c same as a but for ECHAM5 A1B ensemble (2060-2100, 167 tracks). Cyclone tracks displayed individually, maximum intensification phase marked with blue dots
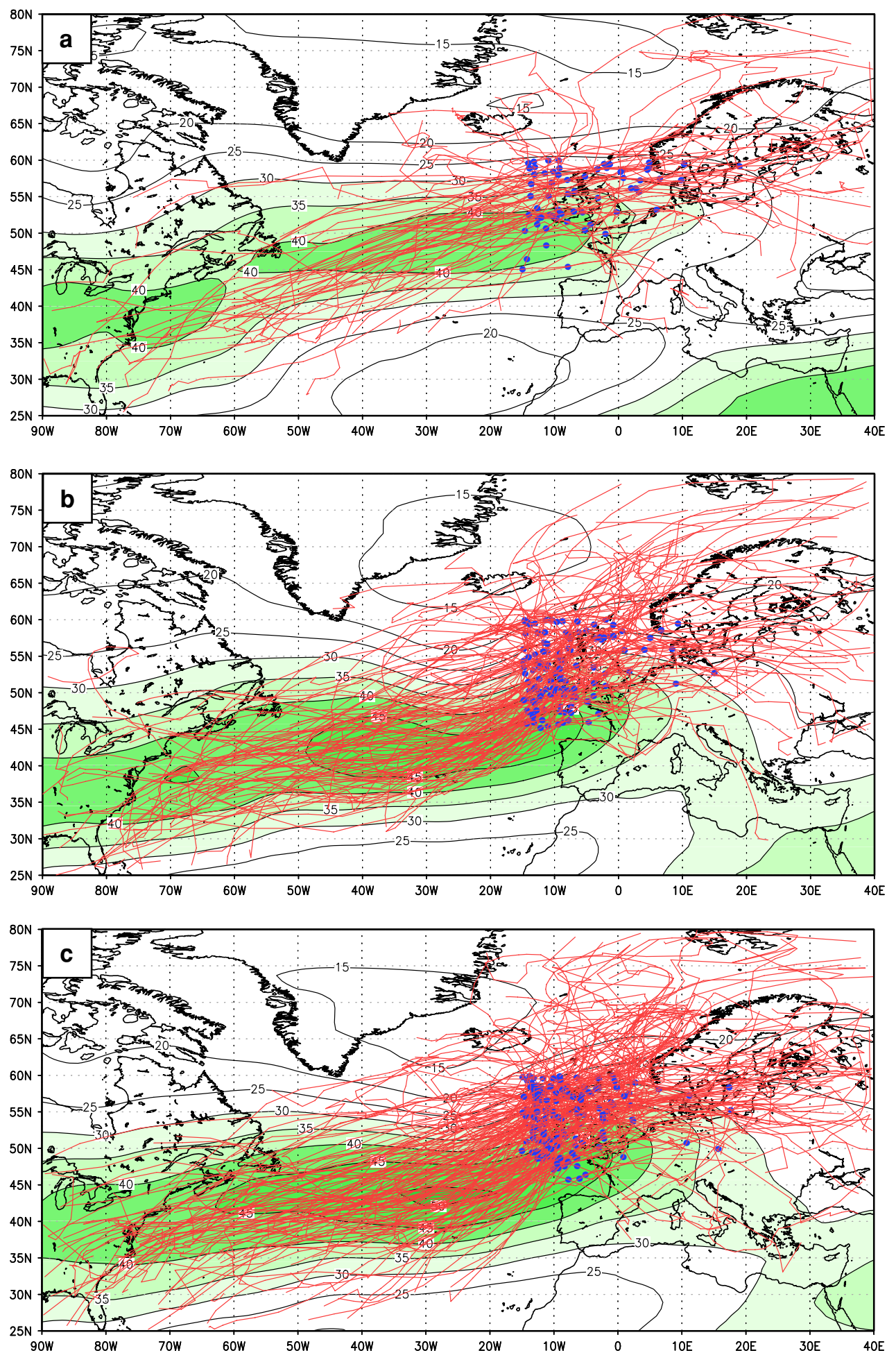

Finally, one of the most relevant results of the present study is the detection of the increase of both track density and intensity for extreme cyclones near the British Isles (Fig. 14) under ACC. This result is even more evident if the analysis is restricted to very intense storms undergoing strong intensification close to Europe (Fig. 19). These patterns of change go well with Pinto et al. (2007a), who analysed the changes of loss potentials for several European countries based on the same GCM simulations. They found an enhancement of the average annual losses under ACC, and in particular a very strong increase in standard deviation, indicating a strong tendency towards more extreme single events. Similar results were obtained by Leckebusch et al. (2007) for an ensemble of four different 
Fig. 19 Changes in cyclone track density and associated jet stream $250 \mathrm{hPa}$ based on ECHAM5 for A1B minus 20C ensemble average (2060-2100 vs. 1960-2000). Black lines correspond to changes for cyclone track density (cyclone days/winter), areas with significant differences (95th and 99th confidence levels) are in colour ( $T$ test on winter basis). Green lines correspond to changes for jet stream $250 \mathrm{hPa}$ $\left(\mathrm{m} \mathrm{s}^{-1}\right.$ ) (light green negative, dark green positive), areas with significant differences $(95$ th confidence levels, $T$ test on winter basis) are marked with green dots

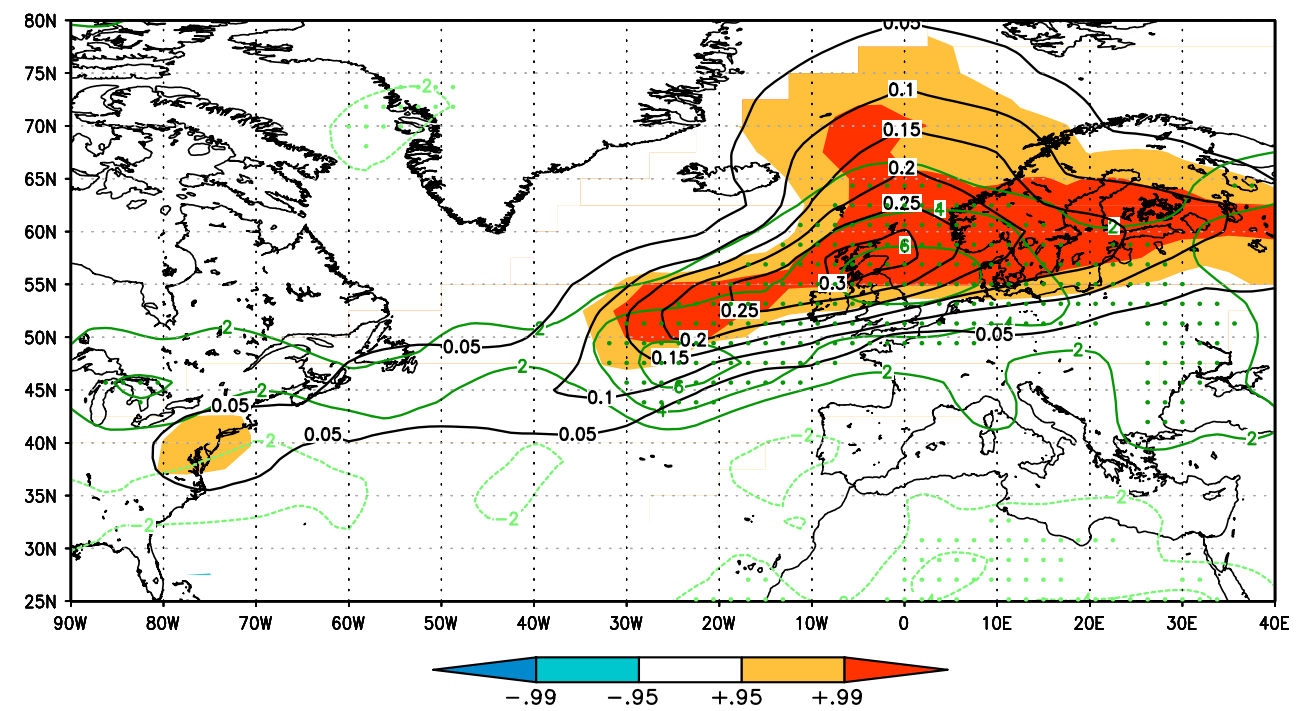

GCMs. While the investigations by Leckebusch et al. (2007) and Pinto et al. (2007a) were based on annual values, it is scientifically challenging to explore to what extent the individual storms contribute to totals, both in terms of integrated losses and on affected areas. The here identified increased number of storms undergoing a strong intensification phase close to Europe corroborates with the assumption that the destructive capacity of (single) storms over Europe may increase. However, further research is necessary to verify this assumption.

In conclusion, the present results show that extreme cyclones have different characteristics to non-extreme cyclones, featuring larger intensities, core pressures, longer lifetimes and cyclone tracks. Further, their growth is associated with extreme values of the four considered environmental variables $\left(\sigma_{400}, \theta_{\mathrm{e}} \operatorname{div}_{250}\right.$, jet 250$)$. Extreme cyclones occur preferentially in (strong) positive NAO phases, when the conditions are best for their development. Under ACC, the ECHAM5 GCM shows a reduced number of both extreme and non-extreme cyclones (ca. 10\%). An exception is the region over the NA close to the British Isles, for which an increase in track density and intensity of extreme cyclones is found, irrespective of the NAO phase. This change is associated with an eastward shift of the jet stream into Europe. For all four environmental variables, an increase of the frequency of extreme values near the cyclone cores is detected, but the general relationships between environmental variables and cyclone development remain valid. In particular, an increased number of explosive developments close to Europe is found under ACC, in agreement with the enhanced number of windstorms affecting Europe as found in other studies.

Acknowledgments This work was partially supported by the European Union Programme Energy, Environment and Sustainable Development under contracts EVK2-CT-2001-00118 (MICE) and
GOCE-CT-2003-505593-ENSEMBLES. We would like to kindly thank Erich Roeckner and the MPI for Meteorology (Hamburg, Germany) by order of the Federal Environment Agency for support and providing the ECHAM5 data, and the DKRZ/WDCC (Hamburg, Germany) and RRZK (Köln, Germany) for computer and storage capacity. We are thankful to Sven Ulbrich for helping to prepare some of the figures. We would also like to thank Ian Watterson and one anonymous reviewer for their helpful comments.

Open Access This article is distributed under the terms of the Creative Commons Attribution Noncommercial License which permits any noncommercial use, distribution, and reproduction in any medium, provided the original author(s) and source are credited.

\section{References}

Baehr C, Pouponneau B, Ayrault F, Joly A (1999) Dynamical characterization of the FASTEX cyclogenesis cases. Q J R Meteor Soc 125:3469-3494

Benedict JJ, Lee S, Feldstein SB (2004) A synoptic view of the North Atlantic Oscillation. J Atmos Sci 61:121-144

Bengtsson L, Hodges KI, Roeckner E (2006) Storm tracks and climate change. J Clim 19:3518-3543

Beniston M, Stephenson DB, Christensen OB, Ferro CAT, Frei C, Goyette S, Halsnaes K, Holt T, Jylha K, Koffi B, Palutikof J, Scholl R, Semmler T, Woth K (2007): Future extreme events in European climate: an exploration of regional climate model projections. Clim Change 81:71-95

Blessing S, Fraedrich K, Junge M, Kunz T, Linkheit F (2005) Daily North-Atlantic Oscillation (NAO) index: statistics and its stratospheric polar vortex dependence. Meteorol Z 14:763-769

Bolton D (1980) The computation of equivalent potential temperature. Mon Weather Rev 108:1046-1053

Chang CB, Pepkey DJ, Kreitzberg CW (1984) Latent heat induced energy transformations during cyclogenesis. Mon Weather Rev $112: 357-367$

Deveson ACL, Browning KA, Hewson TD (2002) A classification of FASTEX cyclones using a height-attributable quasi-geostrophic vertical-motion diagnostic. Q J R Meteorol Soc 128:93-117

Feldstein SB (2003) The dynamics of NAO teleconnection pattern growth and decay. Q J R Meteor Soc 129:901-924 
Fink AH, Brücher T, Ermert V, Krüger A, Pinto JG (2008) The European storm kyrill in January 2007. Nat Hazards Earth Syst Sci (submitted)

Franzke C, Lee S, Feldstein SB (2004) Is the North Atlantic Oscillation a breaking wave? J Atmos Sci 61:145-160

Gray SL, Dacre HF (2006) Classifying dynamical forcing mechanisms using a climatology of extratropical cyclones. Q J R Meteorol Soc 132:1119-1137

Hoskins BJ, Valdes PJ (1990) On the existence of storm tracks. J Atmos Sci 47:1854-1864

Hoskins BJ, Hodges KI (2002) New perspectives on the Northern Hemisphere winter storm tracks. J Atmos Sci 59:1041-1061

Hurrell JW (1995) Decadal trends in the North Atlantic Oscillation: regional temperatures and precipitation. Science 269:676-679

Hurrell JW, Kushnir Y, Ottersen G, Visbek M (2003) An overview of the North Atlantic Oscillation. In: Hurrell JW, Kushnir Y, Ottersen G, Visbeck M (eds) The North Atlantic Oscillation: climate significance and environmental impact. Geophysical monograph series, vol 134, pp 1-35

Jones PD, Jonsson T, Wheeler D (1997) Extension to the North Atlantic Oscillation using early instrumental pressure observations from Gibraltar and South-West Iceland. Int $\mathrm{J}$ Climatol 17:1433-1450

Jungclaus JH, Botzet M, Haak H, Keenlyside N, Luo JJ, Latif M, Marotzke J, Mikolajewicz U, Roeckner E (2005) Ocean circulation and tropical variability in the coupled model ECHAM5/MPI-OM. J Clim 19:3952-3972

Kalnay E, Kanamitsu M, Kistler R, Collins W, Deaven D, Gandin L, Iredell $\mathrm{M}$, Saha $\mathrm{S}$, White $\mathrm{G}$, Woollen $\mathrm{J}$, Zhu Y, Leetmaa A, Reynolds B, Chelliah M, Ebisuzaki W, Higgins W, Janowiak J, Mo KC, Ropelewski C, Wang J, Jenne R, Joseph D (1996) The NCEP-NCAR 40-year reanalysis project. Bull Am Meteorol Soc 77:437-472

Kistler R, Kalnay E, Collins W, Saha S, Woollen J, Chelliah M, EbiSuzaki W, Kanamitsu M, Kouski V, Van Den Dool H, Jenne R, Fiorino R (2001) The NCEP/NCAR 50-year reanalysis: monthly-means CD-ROM and documentation. Bull Am Meteorol Soc 82:247-267

Klawa M, Ulbrich U (2003) A model for the estimation of storm losses and the identification of severe winter storms in Germany. Nat Hazards Earth Syst Sci 3:725-732

Kurz M (1990) Synoptische Meteorologie. Selbstverlag des Deutschen Wetterdienstes, Offenbach, $197 \mathrm{pp}$

Leckebusch GC, Koffi B, Ulbrich U, Pinto JG, Spangehl T, Zacharias S (2006) Analysis of frequency and intensity of winter storm events in Europe on synoptic and regional scales from a multimodel perspective. Clim Res 31:59-74

Leckebusch GC, Ulbrich U, Fröhlich EL, Pinto JG (2007) Property loss potentials for European mid-latitude storms in a changing climate. Geophys Res Lett 34:L05703. doi:10.1029/2006GL027663

Löptien U, Ruprecht E (2005) Effect of synoptic systems on the variability of the North Atlantic Oscillation. Mon Weather Rev 133:2894-2904

MacDonald BC, Reiter EA (1988) Explosive cyclogenesis over the eastern United States. Mon Weather Rev 116:1568-1586

Marshall J, Kushnir Y, Battisti D, Chang P, Czaja A, Dickson R, Hurrell J, McCartney M, Saravanan R, Visbeck M (2001) North Atlantic climate variability: phenomena, impacts and mechanisms. Int J Climatol 21:1863-1898

Marsland SJ, Haak H, Jungclaus JH, Latif M, Röske F (2003) The Max-Planck-Institute global ocean/sea ice model with orthogonal curvilinear coordinates. Ocean Modell 5:91-127

Meehl GA, Stocker TF, Collins WD, Friedlingstein P, Gaye AT, Gregory JM, Kitoh A, Knutti R, Murphy JM, Noda A, Raper SCB, Watterson IG, Weaver AJ, Zhao Z-C (2007) Global climate projections. In: Solomon S, Qin D, Manning M, Chen Z,
Marquis M, Averyt KB, Tignor M, Miller HL (eds) Climate change 2007: the physical science basis. Contribution of Working Group I to the fourth assessment report of the Intergovernmental Panel on Climate Change. Cambridge University Press, Cambridge

Murray RJ, Simmonds I (1991) A numerical scheme for tracking cyclone centres from digital data. Part I: Development and operation of the scheme. Aust Meteorol Mag 39:155-166

Nakićenović N, et al. (2000) Emission scenarios. A Special Report of Working Group III of the Intergovernmental Panel on Climate Change. Cambridge University Press, London, 599 pp

Nuss WA, Anthes RA (1987) A numerical investigation of low-level processes in rapid cyclogenesis. Mon Weather Rev 115:27282743

Osborn TJ (2004) Simulating the winter North Atlantic Oscillation: the roles of internal variability and greenhouse gas forcing. Clim Dyn 22:605-623

Petterssen S, Smebye SJ (1971) On the development of extratropical cyclones. Q J R Meteorol Soc 97:457-482

Pinto JG, Spangehl T, Ulbrich U, Speth P (2005) Sensitivities of a cyclone detection and tracking algorithm: individual tracks and climatology. Meteorol Z 14:823-838

Pinto JG, Spangehl T, Ulbrich U, Speth P (2006) Assessment of winter cyclone activity in a transient ECHAM4-OPYC3 GHG experiment. Meteorol Z 15:279-291

Pinto JG, Fröhlich EL, Leckebusch GC, Ulbrich U (2007a) Changes in storm loss potentials over Europe under modified climate conditions in an ensemble of simulations of ECHAM5/MPIOM1. Nat Hazards Earth Syst Sci 7:165-175

Pinto JG, Ulbrich U, Leckebusch GC, Spangehl T, Reyers M, Zacharias S (2007b) Changes in storm track and cyclone activity in three SRES ensemble experiments with the ECHAM5/MPIOM1 GCM. Clim Dyn 29:195-210

Raible CC, Yoshimori M, Stocker TF, Casty C (2007) Extreme midlatitude cyclones and their implications to precipitation and wind speed extremes in simulations of the Maunder Minimum versus present day conditions. Clim Dyn 28:409-423

Raible CC (2007) On the relation between extremes of midlatitude cyclones and the atmospheric circulation using ERA40. Geophys Res Lett 34:L07703. doi:10.1029/2006GL029084

Roeckner E, Bäuml G, Bonaventura L, Brokopf R, Esch M, Giorgetta M, Hagemann, Kirchner I, Kornblueh L, Manzini E, Rhodin A, Schlese U, Schulzweida U, Tompkins A (2003) The atmospheric general circulation model ECHAM 5. PART I: Model description. Max-Plank Institut Meteorol Rep 349, Hamburg, Germany

Roeckner E, Brokopf R, Esch M, Giorgetta M, Hagemann, Kornblueh L, Manzini E, Schlese U, Schulzweida U (2006) Sensitivity of simulated climate to horizontal and vertical resolution in the ECHAM5 atmosphere model. J Clim 19:3771-3791

Rogers JC (1997) North Atlantic storm track variability and its association to the North Atlantic Oscillation and climate variability of Northern Europe. J Clim 10:1635-1647

Sanders F (1986) Explosive cyclogenesis in the west central North Atlantic Ocean 1981-1984. Part I: Composite structure and mean behavior. Mon Weather Rev 114:1781-1794

Schneidereit A, Blender R, Fraedrich K, Lunkheit F (2007) Iceland climate and North Atlantic cyclones in ERA40 reanalyses. Meteorol Z 16:17-23

Schultz DM, Keyser D, Bosart LF (1998) The effect of large-scale flow on low-level frontal structure and evolution in midlatitude cyclones. Mon Weather Rev 126:1767-1791

Serreze MC, Carse F, Barry RG, Rogers JC (1997) Icelandic low cyclone activity: climatological features, linkages with the NAO and relationships with recent changes elsewhere in the Northern Hemisphere circulation. J Clim 10:453-464 
Sickmöller M. Blender R, K. Fraedrich K (2000) Observed winter cyclone tracks in the northern hemisphere in re-analysed ECMWF data. Q J R Meteorol Soc 126:591-620

Stephenson DB, Pavan V, Collins M, Junge MM, Quadrelli R, participating CMIP2 modelling groups (2006) North Atlantic Oscillation response to transient greenhouse gas forcing and the impact on European winter climate: a CMIP2 multi-model assessment. Clim Dyn 27:401-420

Thorncroft CD, Hoskins BJ, McIntyre ME (1993) Two paradigms of baroclinic-wave life-cycle behaviour. Q J R Meteorol Soc 119:17-55

Trigo IF (2006) Climatology and interannual variability of stormtracks in the Euro-Atlantic sector: a comparison between ERA40 and NCEP/NCAR reanalyses. Clim Dyn 26:127-143

Uccellini LW Johnson DR (1979) The coupling of upper and lower tropospheric jet streaks and implications for the development of severe convective storms. Mon Weather Rev 107:682-703

Ueno K (1993) Inter-annual variability of surface cyclone tracks, atmospheric circulation patterns, and precipitation patterns in winter. J Meteorol Soc Jpn 71:655-671
Ulbrich U, Christoph M (1999) A shift of the NAO and increasing storm track activity over Europe due to anthropogenic greenhouse gas forcing. Clim Dyn 15:551-559

Ulbrich U, Fink AH, Klawa M, Pinto JG (2001) Three extreme storms over Europe in December 1999. Weather 56:70-80

Ulbrich U, Leckebusch GC, Pinto JG (2008a) Cyclones in the present and future climate: a review. Theor Appl Climatol (submitted)

Ulbrich U, Pinto JG, Kupfer H, Leckebusch GC, Spangehl T, Reyers M (2008b) Northern Hemisphere storm tracks in an ensemble of IPCC climate change simulations. J Clim (in press)

Walker GT (1924) Correlations in seasonal variations of weather IX. Mem India Meteorol Dept 24:275-332

Wanner H, Bronnimann S, Casty C, Gyalistras D, Luterbacher J, Schmutz C, Stephenson DB, Xoplaki E (2001) North Atlantic Oscillation-concepts and studies. Surv Geophys 22:321-382

Young MV, Grahame NS (1999) Forecasting the Christmas Eve storm 1997. Weather 54:382-391

Watterson IG (2006) The intensity of precipitation during extratropical cyclones in global warming simulations: a link to cyclone intensity? Tellus 58A:82-97 